Article

\title{
The Effect of Aerosol Radiative Heating on Turbulence Statistics and Spectra in the Atmospheric Convective Boundary Layer: A Large-Eddy Simulation Study
}

\author{
Cheng Liu ${ }^{1}(\mathbb{D})$, Jianping Huang ${ }^{1, *}$, Evgeni Fedorovich ${ }^{2}$, Xiao-Ming $\mathrm{Hu}^{2,3}{ }^{(\mathbb{D})}$, Yongwei Wang ${ }^{1}$ (i) \\ and Xuhui Lee ${ }^{1,4}$ \\ 1 Yale-NUIST Center on Atmospheric Environment, International Joint Laboratory on Climate and \\ Environment Change (ILCEC)/Key Laboratory of Meteorological Disaster, Ministry of \\ Education (KLME)/Collaborative Innovation Center on Forecast and Evaluation of Meteorological \\ Disasters (CIC-FEMD), Nanjing University of Information Science \& Technology, Nanjing 210044, China; \\ chengliu6542@gmail.com (C.L.); wyw@nuist.edu.cn (Y.W.); xuhui.lee@yale.edu (X.L.) \\ 2 School of Meteorology, University of Oklahoma, Norman, OK 73072, USA; fedorovich@ou.edu (E.F.); \\ xhu@ou.edu (X.-M.H.) \\ 3 Center for Analysis and Prediction of Storms, University of Oklahoma, Norman, OK 73072, USA \\ 4 School of Forestry and Environmental Studies, Yale University, New Haven, CT 06511, USA \\ * Correspondence: jianping.huang@noaa.gov
}

Received: 21 June 2018; Accepted: 1 September 2018; Published: 5 September 2018

\begin{abstract}
Turbulence statistics and spectra in a radiatively heated convective boundary layer (CBL) under aerosol pollution conditions are less investigated than their counterparts in the clear CBL. In this study, a large-eddy simulation (LES) coupled with an aerosol radiative transfer model is employed to determine the impact of aerosol radiative heating on CBL turbulence statistics. One-dimensional velocity spectra and velocity-temperature cospectra are invoked to characterize the turbulence flow in the CBL with varying aerosol pollution conditions. The results show that aerosol heating makes the profiles of turbulent heat flux curvilinear, while the total (turbulent plus radiative) heat flux profile retains the linear relationship with height throughout the CBL. The horizontal and vertical velocity variances are reduced significantly throughout the radiatively heated CBL with increased aerosol optical depth (AOD). The potential temperature variance is also reduced, especially in the entrainment zone and near the surface. The velocity spectral density tends to be smaller overall, and the peak of the velocity spectra is shifted toward larger wavenumbers as AOD increases. This shift reveals that the energy-containing turbulent eddies become smaller, which is also supported by visual inspection of the vertical velocity pattern over horizontal planes. The modified CBL turbulence scales for velocity and temperature are found to be applicable for normalizing the corresponding profiles, indicating that a correction factor for aerosol radiative heating is needed for capturing the general features of the CBL structure in the presence of aerosol radiative heating.
\end{abstract}

Keywords: aerosol radiative heating; spectral analysis; convective boundary layer; large-eddy simulation; turbulence statistics

\section{Introduction}

In the atmospheric convective boundary layer (CBL), turbulence is the main mechanism for the transport and mixing of heat, moisture, and air pollutants [1]. Turbulence in the CBL is generated primarily by the buoyancy forcing associated with the solar heating of the underlying surface, 
with wind shears being the secondary contributor $[2,3]$. Turbulent organized structures (TOS) are often observed in the CBL on large-scale motions. Turbulence kinetic energy (TKE) in the CBL is mainly produced by the largest eddies with sizes roughly equal to the boundary layer depth, and dissipated by the smallest eddies on the order of a few millimeters in size [4]. Previous studies show that the energy distribution among eddies of different sizes appears to be relatively steady with time when spectra are averaged over an appropriate time period [5]. Typically, statistical approaches are used to describe the behavior and effect of turbulence in the CBL. The turbulence structure of the CBL plays a critical role in determining the shapes of the profiles of meteorological variables within the CBL [6]. CBLs with a heavy aerosol loading are often observed in developing countries such as China, where urbanization and industrialization have been rapidly growing over past several decades [7]. However, the turbulence structure of the CBL with heavy aerosol loading is not adequately studied, which is mainly due to the lack of field experiments and high-resolution numerical simulations.

Aerosols exert a complex impact on turbulence within the CBL through aerosol radiative effect. In the presence of aerosols, the downward shortwave radiation reaching the surface is reduced, and surface heat flux is decreased. As a result, turbulent motions become less vigorous. On the other hand, aerosols absorb some solar radiation and contribute to radiative heating, even though some of the radiation is scattered in various directions depending on the aerosols' scattering property (e.g., single scatter albedo, SSA). The vertical redistribution of heat induced by aerosols modifies the CBL thermal structure, changes the static stability of the CBL, and ultimately affects the turbulent motions and the CBL growth dynamics [8-12]. Aerosol radiative heating within the CBL was often observed with substantial effects. For instance, the strong aerosol heating of the CBL with a rate of $4-5 \mathrm{~K} \mathrm{~d}^{-1}$ was observed during the Flatland boundary layer experiments [13]. Much higher aerosol heating with a rate of $10 \mathrm{~K} \mathrm{~d}^{-1}$ was reported by Raga et al. [14] for the case with an aerosol optical depth (AOD) of 0.55 and a uniform vertical distribution of aerosols. Here, AOD represents the degree to which the aerosol impedes the transmission of light through the atmosphere. Meanwhile, the modeling results showed similar aerosol radiative heating rate with values of about $5 \mathrm{~K} \mathrm{~d}^{-1}$ and $8 \mathrm{~K} \mathrm{~d}^{-1}$ at noon for aerosol with SSA equal to 0.9 and 0.8 , respectively [8]. However, how aerosol radiative heating affects the detailed CBL turbulence structure is still not well understood.

Numerical models provide a feasible way to quantify the impact of the aerosol radiative effect on the CBL turbulence structure. Typically, studies of the aerosol radiative effect on the CBL structure are conducted by using mesoscale atmospheric models (e.g., Weather Research and Forecast model coupled with chemical module, WRF-Chem) $[11,15,16]$ or one-dimensional conceptual models $[8,17]$. The turbulence motions cannot be resolved explicitly in such models, which are highly dependent on the boundary-layer parameterizations. The large-eddy simulation (LES) has lately become a powerful tool that is widely used in the investigation of the detailed features of the atmospheric boundary layer turbulence structure, convective entrainment, exchanges of momentum, heat, and moisture between the atmosphere and underlying surface, and other fine-scale processes [18-22]. Although the LES can only be applied over relatively small domains, often with idealized boundary conditions, the easily controlled conditions and provision for large sample size make the LES particularly suitable to get insight into how an extra forcing (e.g., aerosol radiative heating) affects the thermodynamics of the boundary layer [23]. LES has been demonstrated to capture more realistic effects of the boundary-layer turbulence than the parameterizations employed in mesoscale and larger-scale models. Barbaro et al. [10] first used an LES to study the influence of aerosol heating on the flow structure in the CBL, but their investigation is limited to the CBL cases with slight aerosol loading, and the spectral behavior of turbulence in the aerosol-loaded CBL has not been addressed.

The CBL flow structure can be well characterized by turbulence statistics, which usually include mean values of meteorological variables (first-order statistics), variances and covariances (second-order statistics; usually associated with turbulent fluxes), and skewness (third-order statistics and their derivatives). Typically, the profile of mean potential temperature $(\theta)$ in the shear-free and aerosol-free CBL displays a three-layered structure, with a large vertical gradient in the surface layer, 
a mixed region (layer) with nearly constant mean $\theta$, and an entrainment zone with a local potential temperature gradient larger than that of the overlying free atmosphere [2,24]. The heat flux, which is typically a combination of upward heat flux from the surface and downward entrainment flux [25], changes linearly with height in the quasi-steady CBL $[26,27]$. The variance of horizontal velocity, which is an important statistical parameter representing turbulent flow fluctuations, reaches its maximum value near the surface, while the variance of the vertical velocity component has its maximum in the lower middle portion of the CBL. The potential temperature variance attains its maximum in the entrainment zone, which is the region of the large vertical mean temperature gradient. The skewness of vertical velocity, which is an indicator of the asymmetry of vertical motion, is mostly positive throughout the CBL, and increases with height away from the surface $[28,29]$. These typical features of the CBL turbulence characteristics have been discussed extensively in many studies, and form a basis of our current understanding of the aerosol-free CBL turbulence structure. However, it is not known whether these characteristics would be representative of the structure of the aerosol-polluted CBL.

In a shear-free and aerosol-free CBL, the following traditional Deardorff [30] convective scales for velocity and temperature in the mixed layer apply:

$$
w_{*}=\left(\frac{g}{\theta_{0}} Q_{s} z_{i}\right)^{1 / 3}, \theta_{*}=Q_{s} / w_{*}
$$

where $w_{*}$ is convective velocity scale, $g$ is the gravity acceleration, $\theta_{0}$ is a constant reference potential temperature ( $290 \mathrm{~K}$ in this study), $z_{i}$ is boundary layer depth, $\theta_{*}$ is temperature scale and $Q_{s}$ is the surface kinematic heat flux. Being normalized with these convective scales, the profiles of turbulence statistics in shear-free CBLs appear in a self-similar manner. However, it is not known whether such traditional scaling parameters are applicable for the CBL with aerosol loading conditions.

Furthermore, spectral analysis is another useful technique for describing scales and patterns of atmospheric turbulent eddy motions [31]. In the classic paper of Kaimal [32], turbulence spectra and cospectra in the atmospheric surface layer converge to a single universal curve in the inertial subrange with appropriate normalization. Subsequently, many observational studies of velocity and temperature spectra (e.g., Moraes et al. [33]) demonstrated that spectra within the atmospheric surface layer follow Monin-Obukhov similarity theory (MOST). The high-wavenumber behavior of spectra is determined by the local isotropy of small-scale turbulence. Velocity and temperature spectra as functions of wavenumber in a given direction (e.g., $k_{x}$, if fluctuations are measured in the $x$ direction) typically show a power law behavior with a form of $k_{x}{ }^{-5 / 3}$ within the inertial subrange. However, due to difficulties in sampling the upper part of the CBL, most of the spectral analyses are limited to near-surface. With high-resolution simulation data (e.g., LES) available, the spectral analysis can be extended to higher levels within the CBL [34-36]. The CBL velocity spectra have been analyzed in terms of the effects of the temporal discretization [37], model grid mesh [36], and numerical scheme used [38]. To the best of our knowledge, no studies have analyzed the spectral characteristics of turbulence in the CBL with aerosol radiative heating.

In our previous study, Liu et al. [39] used a LES coupled with a radiative transfer model to mainly investigate the impact of aerosol radiative heating on the CBL entrainment. In that study, a zero-order model (ZOM) entrainment equation accounting for the aerosol radiative heating effect is derived and careful validated against the LES outputs. In this study, some of the LES data from Liu et al. [39] are further employed to complement the numerical analyses by investigating the impact of aerosol radiative heating on the CBL turbulence statistics (e.g., mean flow variables, variances and covariances, skewness) and spectra. By doing these analyses, our specific objectives are to: (1) investigate the impact of aerosol radiative heating on various CBL turbulence statistics, (2) determine the spectral characteristics of turbulence in the radiatively heated CBL, and (3) find suitable scaling parameters for velocity and temperature in the CBL with aerosol loading. The rest of paper is organized as follows. The employed modeling approach and simulation setups are briefly described in Section 2. The results 
of the impact of aerosol radiative heating on turbulence statistics and spectra are discussed in Section 3, and the conclusions and summary are presented in Section 4.

\section{Model and Methodology}

\subsection{Model Description}

A LES-coupled radiative transfer model is used in this study. Details about the model coupling are given in Liu et al. [39]. The LES code was initially developed by Moeng et al. [19] and further improved by Sullivan et al. [20], Patton et al. [40], and Huang et al. [25]. In the coupled code, an aerosol radiative heating term $(\partial R / \partial z)$ is added to the filtered LES heat balance equation for potential temperature, where $z$ is the height above the ground, $R$ is the shortwave radiative flux, which is determined by using the Santa Barbara Discrete Ordinates Radiative Transfer (DISORT) Atmospheric Radiative Transfer (SBDART) model [41]. The basic input parameters for SBDART include longitude, latitude, time, height above the ground, and surface albedo, plus aerosol optical parameters such as AOD, single scattering albedo (SSA), and asymmetric factor $\left(g_{f}\right)$. Aerosols are assumed to be uniformly distributed within the CBL and confined to its interior. The uniform distribution is a common way of setup in the simulation studies (e.g., Raga et al. [14]; Barbaro et al. [10]), and has been demonstrated in many observational studies (e.g., Steyn et al. [42]; Ferrero et al. [43]; Ware et al. [44]) for the well-mixed conditions of the convective boundary layer. The radiative flux $R$ is calculated at the given heights by means of the radiative transfer equation [45], and the corresponding aerosol radiative heating rate $(\partial R / \partial z)$ is thereby calculated and prescribed at each LES model level. As a reminder, the chemical composition, population, and size distribution of aerosols are not changed in our simulations. Aerosol particle-resolved Lagrangian models could be used to investigate the aerosol radiative effect (e.g., Kleeman et al. [46]; Rimer et al. [47]), which provides certain advantages with respect to a more realistic representation of the optical properties of aerosols as compared to the modeling method employed in our study.

Meanwhile, the surface downward shortwave radiation obtained from SBDART is fed into the land surface module (LSM, Huang et al. [21]), and the LSM-predicted surface sensible and latent heat fluxes are used in the LES to drive the development of the CBL. The boundary layer top, $z_{i}$, which is diagnosed as the height where the simulated heat flux reaches its minimum value, is delivered to SBDART for determining the height limit of aerosol distribution.

\subsection{Numerical Experiments}

The settings of the LES numerical experiments are presented in Table 1. The simulation domain covers a cuboid of $5 \mathrm{~km} \times 5 \mathrm{~km} \times 1.92 \mathrm{~km}$ with grid spacing of $50 \mathrm{~m}, 50 \mathrm{~m}$, and $20 \mathrm{~m}$ in the $x, y$, and $z$ directions, respectively. As illustrated in Figure 1 , the potential temperature field is initialized with a two-layer profile with a constant value of $290 \mathrm{~K}$ below the CBL top (i.e., $640 \mathrm{~m}$ ) and a certain potential temperature gradient above (e.g., $3 \mathrm{~K} \mathrm{~km}^{-1}, 6 \mathrm{~K} \mathrm{~km}^{-1}$, and $9 \mathrm{~K} \mathrm{~km}^{-1}$ ). A dry and cloud-free CBL is considered to remove the impact of water vapor and clouds. Geostrophic wind is not included (i.e., shear free) in all of the simulated cases due to weak winds (e.g., less than $5.0 \mathrm{~m} \mathrm{~s}^{-1}$ ) observed on heavy aerosol pollution events, which has a negligible impact on CBL development (e.g., Pino et al. [48]; Liu et al. [3]). Six $A O D$ values (i.e., $\mathrm{AOD}=0,0.3,0.6,0.9,1.2,1.5$ ) represent the scenarios with varying aerosol pollution conditions, the AOD values set in the numerical experiments are based on the surface observational and satellite-retrieved data in China and other areas around the globe (e.g., Kaufman [49]; Tao et al. [50]). A total of 18 LES cases are completed through combining three free atmospheric potential temperature gradients and six AOD values. SSA $=0.9$ and $g_{f}=0.6$ were used in this study according to the observations conducted in the Yangtze River Delta region, China (Liu et al. [51]). The simulated cases in this study represented the CBLs at 12:00 on 24 January 2015. Latitude and longitude are set to $32.21^{\circ} \mathrm{N}$ and $118.70^{\circ} \mathrm{E}$, respectively. All of the flow statistics are calculated over 200 time-step intervals and averaged over the horizontal plane after the CBL flow 
reaches a quasi-steady regime, as described in Patton et al. [40] and Huang et al. [25]. The spin-up time is about $1 \mathrm{~h}$, which slightly varies among the different simulated cases.

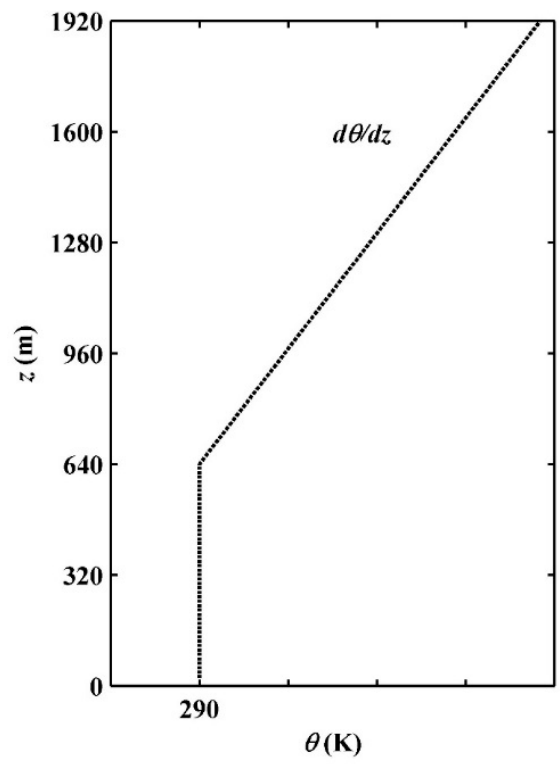

Figure 1. Initial vertical profile of potential temperature. The potential temperature gradient in free atmosphere $(d \theta / d z)$ varies from $3 \mathrm{~K} \mathrm{~km}^{-1}$ to $9 \mathrm{~K} \mathrm{~km}^{-1}$. $\theta$ : potential temperature; $z$ : height above the ground.

Table 1. Settings of large-eddy simulation (LES) experiments. CBL: convective boundary layer. $d \theta / d z$ : the potential temperature gradient in free atmosphere. CTL: control case with AOD $=0$. A03: aerosol case with $\mathrm{AOD}=0.3$, and similarly for the others.

\begin{tabular}{ll}
\hline Characteristic & Setting \\
\hline Domain size & $5 \mathrm{~km} \times 5 \mathrm{~km} \times 1.92 \mathrm{~km}$ \\
Grid spacing & $50 \mathrm{~m} \times 50 \mathrm{~m} \times 20 \mathrm{~m}$ \\
Temperature gradient above CBL & $d \theta / d z=3 \mathrm{~K} \mathrm{~km}^{-1}, 6 \mathrm{~K} \mathrm{~km}^{-1}$, and $9 \mathrm{~K} \mathrm{~km}^{-1}$ \\
Time step & Determined from a numerical stability constraint, varies from $1.6 \mathrm{~s}$ to $2.0 \mathrm{~s}$ \\
Lateral boundary layer conditions & Periodic \\
Upper boundary layer conditions & A radiation boundary layer condition [52] \\
Lower boundary layer conditions & No slip for velocity and Monin-Obukhov similarity \\
Aerosol optical depth (AOD) & CTL: 0, A03: 0.3, A06: 0.6, A09: 0.9, A12: 1.2, A15: 1.5 \\
Single scattering albedo (SSA) & 0.9 \\
Asymmetry factor $\left(g_{f}\right)$ & 0.6 \\
\hline
\end{tabular}

\section{Results and Discussions}

\subsection{Flow Visualization}

We first investigate the impact of aerosol radiative heating on the spatial structure of the velocity and potential temperature fields. Figure 2 demonstrates horizontal $(x-y)$ slices of the vertical velocity $(w)$ at $z / z_{i}=0.1$ with different AOD values under free-convection conditions. Apparently, the vertical velocity field is formed of cellular turbulent organized structures (TOSs) in all of the CBL cases with different AOD values. The TOSs consist of two components: a network with a narrow range of velocity isopleth, and a set of wider polygon-like regions. The former corresponds to the updraft regions (red/positive), while the latter denotes the downdraft areas (blue/negative). Similar structures are also observed in the fields of other scalars such as potential temperature and carbon dioxide $\left(\mathrm{CO}_{2}\right)[21,25,53]$. The TOSs represent the main mechanisms of mass and energy transport in the CBL with varying $A O D$ conditions. A close inspection demonstrates that both updrafts and downdrafts 
tend to be weaker as AOD increases, while the cells become smaller and less vigorous. For instance, the maximum value of vertical velocity is reduced from $2.7 \mathrm{~m} \mathrm{~s}^{-1}$ in the control case (CTL) (Figure 2a, $\mathrm{AOD}=0$ ) to $1.7 \mathrm{~m} \mathrm{~s}^{-1}$ in the aerosol case (A15) (Figure $2 \mathrm{f}, \mathrm{AOD}=1.5$ ). The impact of AOD on the size of TOSs will be further quantified through the spectral analysis in the following section. The reduction of downward shortwave radiation reaching the surface due to the aerosol attenuation effect provides less energy that is available for bottom-up surface heat fluxes to maintain the vigorous turbulence. Similar cellular structures are also observed in the upper portion of the CBL, even though turbulence becomes less active (not shown).
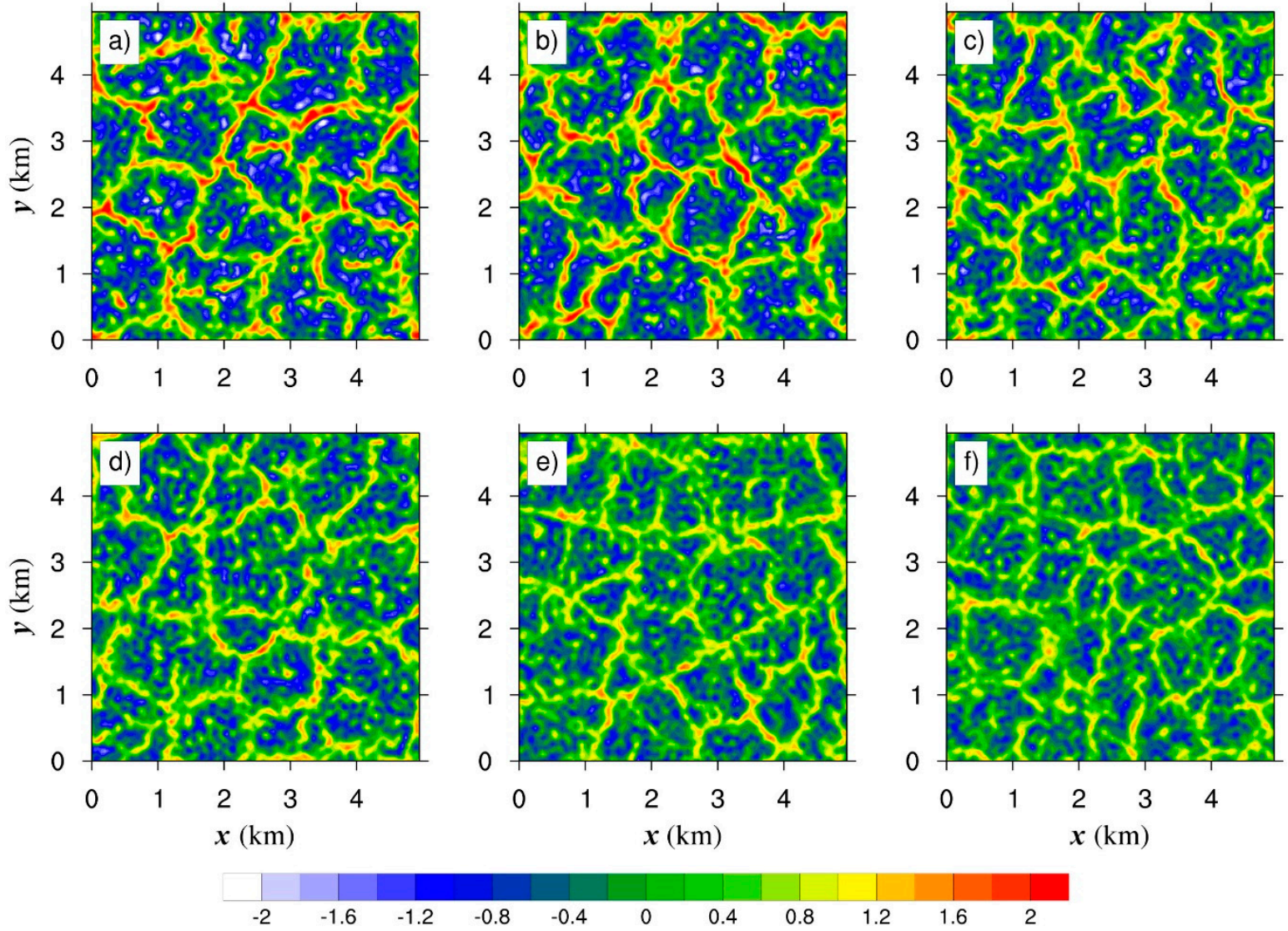

Figure 2. Horizontal $(x-y)$ slices of the vertical velocity at a dimensionless height of $z / z_{i}=0.1$ ( $z$ is the height above the ground, $z_{i}$ is boundary layer depth) averaged over 200 time-steps (about 6-7 min) for the cases of (a) control case (CTL) with $\mathrm{AOD}=0$; (b) aerosol case (A03), AOD = 0.3; (c) aerosol case $(\mathrm{A} 06), \mathrm{AOD}=0.6 ;(\mathbf{d})$ aerosol case $(\mathrm{A} 09), \mathrm{AOD}=0.9 ;(\mathbf{e})$ aerosol case $(\mathrm{A} 12), \mathrm{AOD}=1.2 ;$ and $(\mathbf{f})$ aerosol case $(\mathrm{A} 15), \mathrm{AOD}=1.5$ with the free-atmosphere potential temperature gradient of $6 \mathrm{~K} \mathrm{~km}^{-1}$.

While spatial variation is well represented by the TOSs, the vertical velocity shows large temporal fluctuations. The ramp structure characterized by a sharp rise followed by a gradual decrease is seen in the time series. As shown in Figure 3a, at a fixed central point of the LES domain, the vertical motion alternates from updraft to downdraft (or from downdraft to updraft), and then follows similar cycles as time changes. The ramp structures are closely associated with the TOSs. Similar structures have also been found in other studies [21,54]. As AOD increases to 1.5, the magnitude of temporal fluctuation in $w$ is reduced. The standard deviation (SD) of velocity (see Figure $3 \mathrm{~b}$ ) is reduced from $0.83 \mathrm{~m} \mathrm{~s}^{-1}$ for the CTL case to $0.51 \mathrm{~m} \mathrm{~s}^{-1}$ for the A15 case, indicating that the presence of aerosol weakens the turbulence fluctuation of $w$.

The turbulence structure can be further examined using $x-z$ cross-sections within the vertical velocity field. Figure 4 presents the $x-z$ cross-sections of $w$ for the CBL case with a potential temperature 
gradient of $6 \mathrm{~K} \mathrm{~km}^{-1}$ in the free atmosphere. It is seen that updrafts (red) and downdrafts (blue) occur alternately, and in all of the cases, the total area occupied by downdrafts is much larger than that occupied by updrafts. The intensity of updrafts reduces markedly with increasing AOD. The maximum updraft vertical velocity decreases from $4.5 \mathrm{~m} \mathrm{~s}^{-1}$ (the CTL case) to $2.6 \mathrm{~m} \mathrm{~s}^{-1}$ (the A15 case). Moreover, the vertical extent of the large thermals/updrafts is slightly reduced (by $3 \%$ ) as AOD increases from 0 to 1.5 .
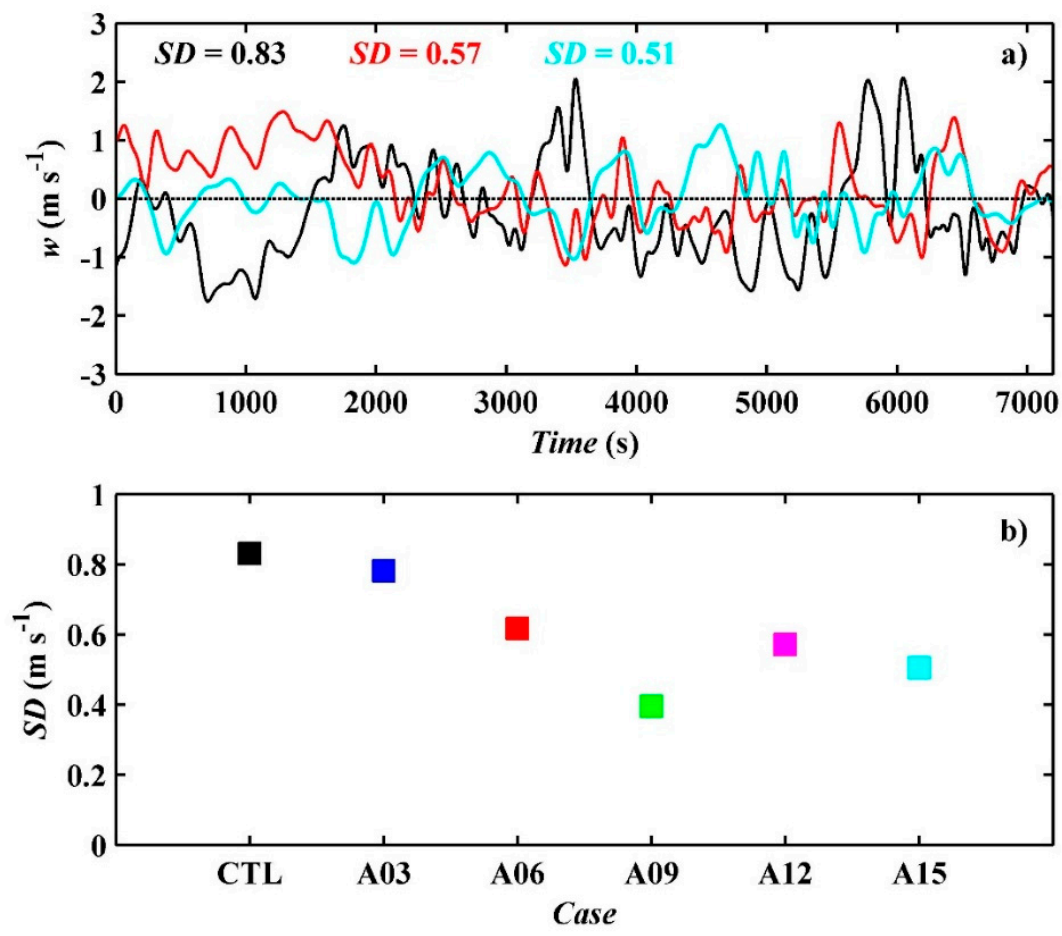

Figure 3. (a) Time series of instantaneous vertical velocity at the central point of the large-eddy simulation (LES) domain, and (b) standard deviation (SD) for different cases. Black: control case (CTL), $\mathrm{AOD}=0$; blue: aerosol case $(\mathrm{A} 03), \mathrm{AOD}=0.3$; red: aerosol case $(\mathrm{A} 06), \mathrm{AOD}=0.6$; green: aerosol case $(\mathrm{A} 09), \mathrm{AOD}=0.9$; magenta: aerosol case $(\mathrm{A} 12), \mathrm{AOD}=1.2 ;$ cyan: aerosol case (A15), $\mathrm{AOD}=1.5$.

The structure of vertical motion in the CBL is closely related to the thermal structure of the atmospheric boundary layer. As seen in Figure 5, the warm regions are collocated with upward motions (black lines), whereas the cold regions overlap with the downdrafts. These TOSs are efficient in transporting heat, water vapors, and other scalars in the CBL. When the aerosol-heating effect is absent (Figure 5a), the structure of the flow is dominated by large-scale rising motions (convective thermals) that originate from the heated surface and compensate for the downdrafts. The thermals are vigorous enough to penetrate into the stably stratified region aloft, producing the lumpy-shape flow structure that is evident in the upper portion of the boundary layer. When the aerosol loading increases slightly, the surface heat fluxes are still sufficiently strong to drive the development of the convective thermals. It is clear that the entrainment zone in these cases is well developed at the CBL top. However, when the aerosol loading increases to a certain levels (e.g., AOD >1.2, Figure 5e,f), the disturbances induced by the rising thermals in the upper portion of the CBL become smaller both in the amplitude and size as compared to their counterparts in the clean CBL. This can be explained by the substantial reduction of surface heat flux that is associated with aerosol shortwave radiation absorption and scattering. Consequently, the updraft motions are not vigorous enough to penetrate into the stably stratified free atmosphere. At the same time, the mean potential temperature in the main portion of the CBL becomes much higher as AOD increases due to the increased aerosol radiative heating effect, even though the surface heat flux is substantially reduced. 

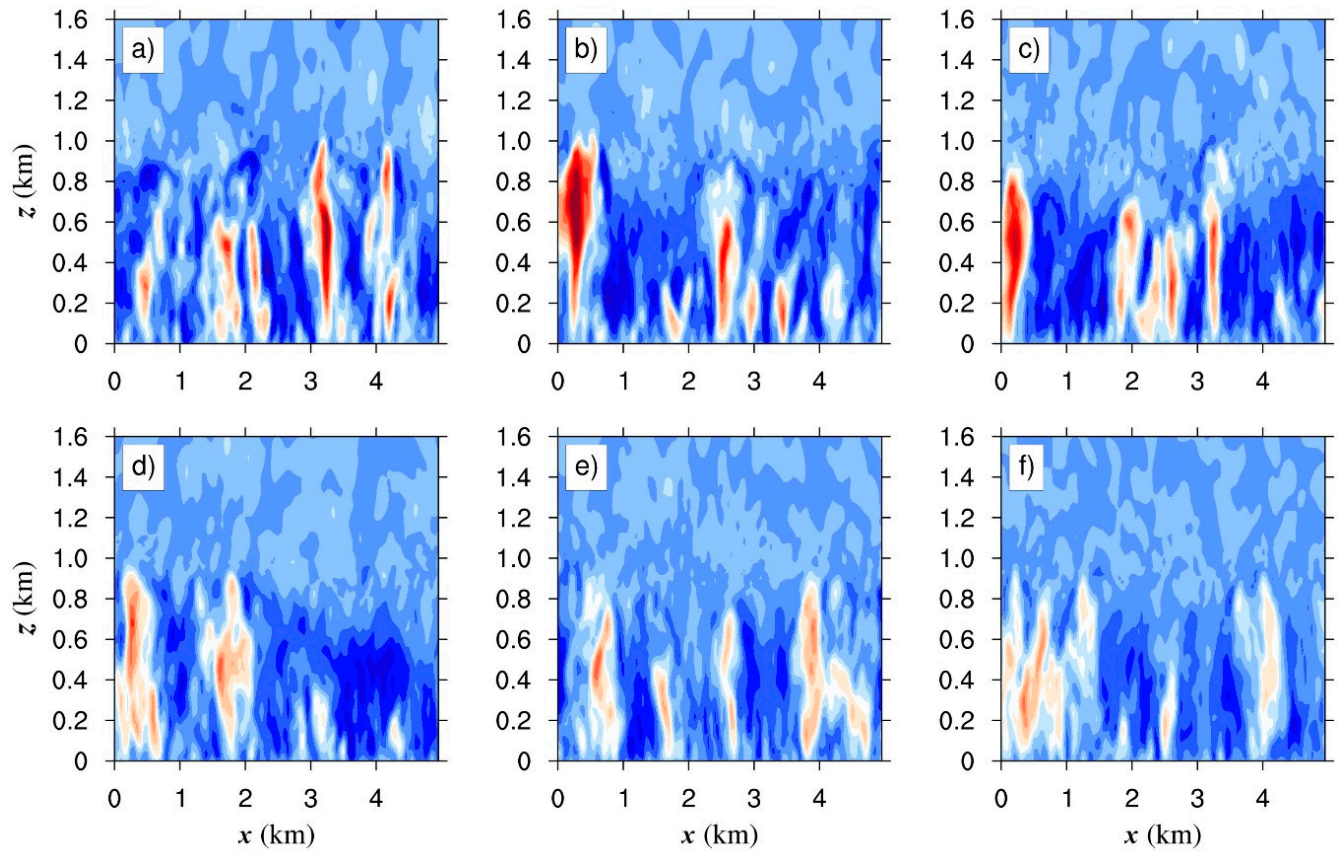

$\begin{array}{llllllllllllllll}-2 & -1.6 & -1.2 & -0.8 & -0.4 & 0 & 0.4 & 0.8 & 1.2 & 1.6 & 2 & 2.4 & 2.8 & 3.2 & 3.6 & 4\end{array}$

Figure 4. $X-z$ cross-sections of the vertical velocity averaged over 200 time-steps (about $6-7 \mathrm{~min}$ ) for the cases of (a) $\mathrm{CTL}, \mathrm{AOD}=0$; (b) $\mathrm{A} 03, \mathrm{AOD}=0.3$; (c) $\mathrm{A} 06, \mathrm{AOD}=0.6$; (d) $\mathrm{A} 09, \mathrm{AOD}=0.9$; (e) $\mathrm{A} 12, \mathrm{AOD}=1.2$; and (f) $\mathrm{A} 15, \mathrm{AOD}=1.5$ with the free-atmosphere potential temperature gradient of $6 \mathrm{~K} \mathrm{~km}^{-1}$.
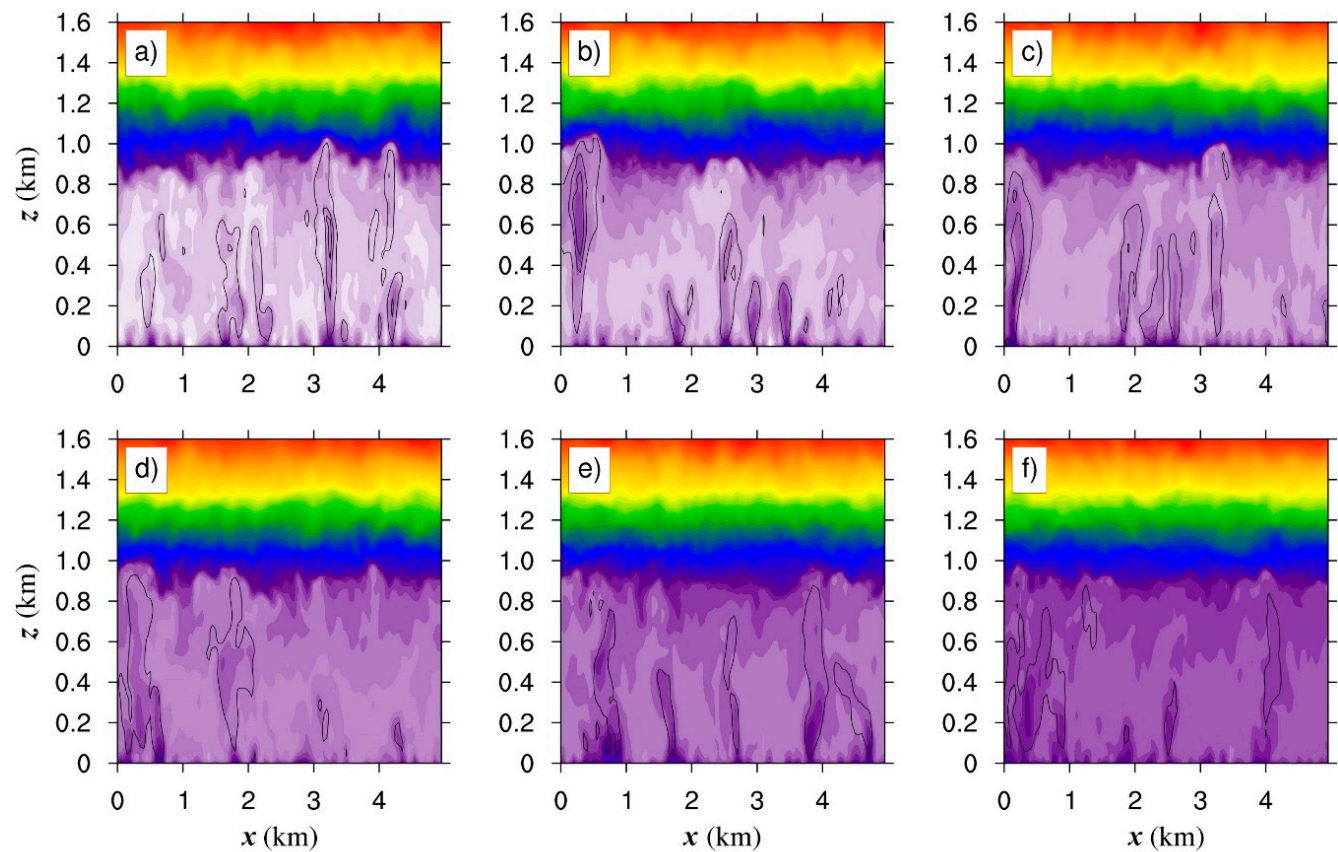

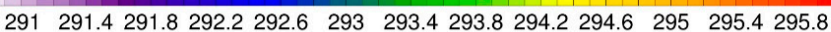

Figure 5. $X-z$ cross-sections of the potential temperature averaged over 200 time-steps (about $6-7 \mathrm{~min}$ ) for the cases of (a) $\mathrm{CTL}, \mathrm{AOD}=0$; (b) $\mathrm{A} 03, \mathrm{AOD}=0.3$; (c) $\mathrm{A} 06, \mathrm{AOD}=0.6$; (d) A09, $\mathrm{AOD}=0.9$; (e) $\mathrm{A} 12, \mathrm{AOD}=1.2$; and (f) $\mathrm{A} 15, \mathrm{AOD}=1.5$ with the free-atmosphere potential temperature gradient of $6 \mathrm{~K} \mathrm{~km}^{-1}$. The black lines represent contour lines of positive vertical velocity, as shown in Figure 4. 


\subsection{Spectral Analysis}

Spectral analysis can be used to further quantify the impact of aerosol radiative heating on the turbulence structure in the CBL. The velocity spectra are calculated in the $x$-direction (or $y$-direction) by following the method described in Kaiser and Fedorovich [55] and Gibbs and Fedorovich [38]. The spectra are calculated first along individual rows in a given horizontal direction and then averaged over the corresponding orthogonal direction. Figure 6 presents the one-dimensional spectra of the resolved $u$ and $w$ components of velocity as functions of wavenumber $k_{x}$ for different AOD cases with the free-atmosphere stratification of $6 \mathrm{~K} \mathrm{~km}^{-1}$. Here, $k_{x}$ is defined as $2 \pi / \lambda_{x}$, where $\lambda_{x}$ is the wavelength along the $x$ coordinate. Logarithmic rather than linear coordinates are traditionally used in the spectral analyses of the atmospheric boundary layer turbulence, given the broad range of representative turbulence scales. The spectra are shown for three different heights: $z / z_{i}=0.1,0.5$, and 0.9 , where $z$ is the height above the ground, and $z_{i}$ is the CBL depth.
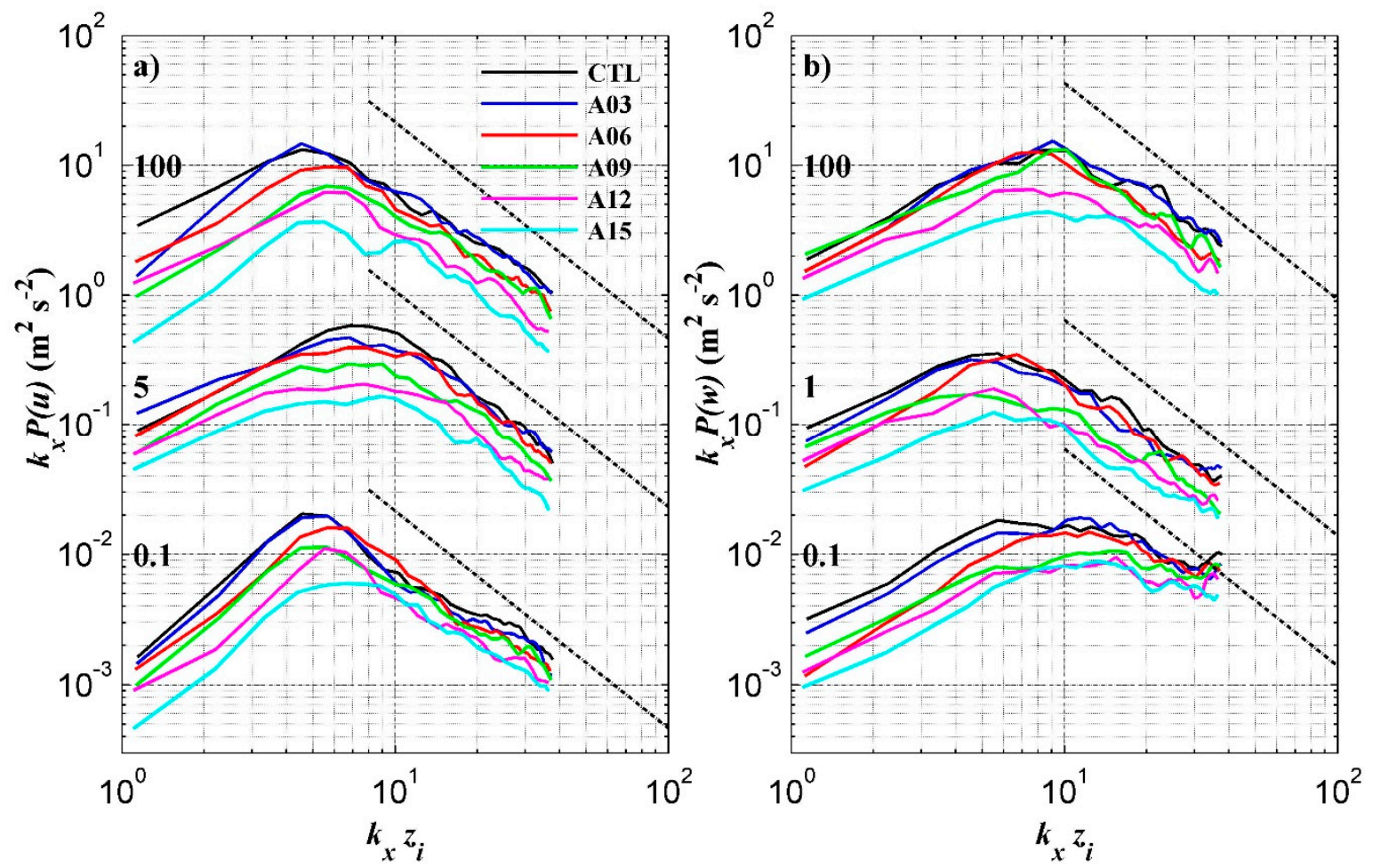

Figure 6. One-dimensional ( $x$ ) spectra of (a) the $u$ velocity component and (b) the $w$ velocity component for the case with different AOD values and the free-atmosphere potential temperature gradient of $6 \mathrm{~K} \mathrm{~km}^{-1}$. The spectra at the top, middle, and bottom are multiplied by numerical factors on the left-hand side of the plot. The straight dashed lines indicate the $-5 / 3$ power law. Black: CTL, $\mathrm{AOD}=0$; blue: $\mathrm{A} 03, \mathrm{AOD}=0.3$; red: $\mathrm{A} 06, \mathrm{AOD}=0.6$; green: $\mathrm{A} 09, \mathrm{AOD}=0.9$; magenta: $\mathrm{A} 12$, $\mathrm{AOD}=1.2$; cyan: $\mathrm{A} 15, \mathrm{AOD}=1.5 . k_{x} z_{i}$ normalized wavenumber; $k_{x} P(u): u$-component spectra; $k_{x} P(w)$ : $w$-component spectra.

The resolved velocity spectra are confined approximately to $1.1<k_{x} z_{i}<40$, corresponding to the wavelengths roughly ranging from the triple grid spacing $(150 \mathrm{~m})$ to the domain length $(5000 \mathrm{~m})$. The $u$-component spectra are shown in Figure 6a. All of the spectral curves have a similar shape, with a peak energy production range, and a $-5 / 3$ slope within the inertial subrange. This behavior is consistent with the data of previous LES studies of CBL [35,36]. In the upper part of the boundary layer $\left(z / z_{i}=0.9\right)$, the magnitude of spectra reduces significantly as AOD increases from 0 to 1.5, particularly for the spectra at small wavenumbers. The normalized wavenumber, at which the energy spectral density has a maximum, slightly shifts toward the large wavenumber values as AOD increases. 
For example, the normalized peak-energy wavenumber shifts from $k_{x} z_{i}=3.4$ in the CTL case (black line) to $k_{x} z_{i}=4.4$ in the A15 case (cyan line). This suggests that the turbulence becomes less intense and the energy-containing turbulent eddies tend to be smaller as AOD increases, which is consistent with our earlier observation of the reduction of cell size (see Figure 2). Similar behavior also takes place in the middle portion of the boundary layer $\left(\right.$ at $\left.z / z_{i}=0.5\right)$. However, the spectral peaks in the middle of the CBL shift to higher wavenumbers than the peaks in the upper portion of the CBL. Correspondingly, the inertial subrange in the spectrum referring to the CBL middle is narrower than in the spectrum at $z / z_{i}=0.9$. Remarkably, the spectral peaks shift back to relatively low wavenumbers at $z / z_{i}=0.1$. This feature has also been found in an LES study of the CBL [36] and in a wind tunnel experiment [55]. One may assume that such behavior is closely associated with the distribution of horizontal velocity variance, reaching its maximum value near the surface and having a secondary maximum within the entrainment zone.

Figure $6 \mathbf{b}$ shows the resolved $w$-component spectra at three different heights for different AOD values. At first glance, the demonstrated spectra have the same shapes as $u$-component spectra in Figure 6a. However, some differences are readily revealed through a careful examination. At $z / z_{i}=0.9$, the peak of the $w$ spectra shifts to higher wavenumbers than the peak of the $u$ spectra. The spectral peak of $w$ in the CBL middle, at $z / z_{i}=0.5$, shifts, in contrast to the spectral peak of the $u$ spectra, toward smaller wavenumbers. This feature is associated with the $w$ variance reaching its maximum in the lower middle portion of the CBL, and then decaying gradually with height. Near the ground (at $z / z_{i}=0.1$ ), a slight departure of the $w$ spectrum from the $-5 / 3$ law is observed at the highest wavenumbers. Meanwhile, the peak of the $w$ spectra displays a markedly broadening with a clear shift toward higher wavenumbers, which may be attributed to the blocking by the wall [36]. The presence of aerosols tends to lower the magnitude of the $w$ spectra, but the spectral shape is still similar to that characteristic of a clean CBL. Meanwhile, the $w$ spectral peak shifts slightly toward high wavenumbers as AOD increases, supporting our previous observation of the energy-containing eddies shrinking with the growing of aerosol loading.

Cospectra of the vertical velocity and potential temperature can be used to identify the contribution of turbulent eddies of different sizes to the heat flux. The heat flux cospectra in Figure 7 do not show a single peak distribution, which is quite different from the spectra of $u$ and $w$. They show a large disparity near the surface $\left(z / z_{i}=0.1\right)$, but decrease with increasing height. This indicates that the impact of aerosol radiative effect on heat flux cospectra is more pronounced near the surface. It is also seen that the cospectra reach their maxima within a relatively large wavenumber range, which means that mostly small-scale eddies transport the thermal energy upwards near the surface. In the presence of a large amount of aerosols in the CBL, the magnitude of cospectra is reduced substantially, and the peak is not apparent as AOD increases to 1.5. At the middle part of the CBL $\left(z / z_{i}=0.5\right)$, a similar reduction trend is found as AOD increases. At the same time, the cospectrum maximum shifts to smaller wavenumbers of about $k_{x} z_{i}=7-10$, pointing to motions with a length scale of the order $z_{i}$ being the main contributors to the heat transport. The magnitude of cospectra continues to decrease toward the boundary-layer top, with cospectra at large AOD values being close to zero, demonstrating that active heat-transporting turbulent motions hardly reach here, in contrast to a clean CBL. 


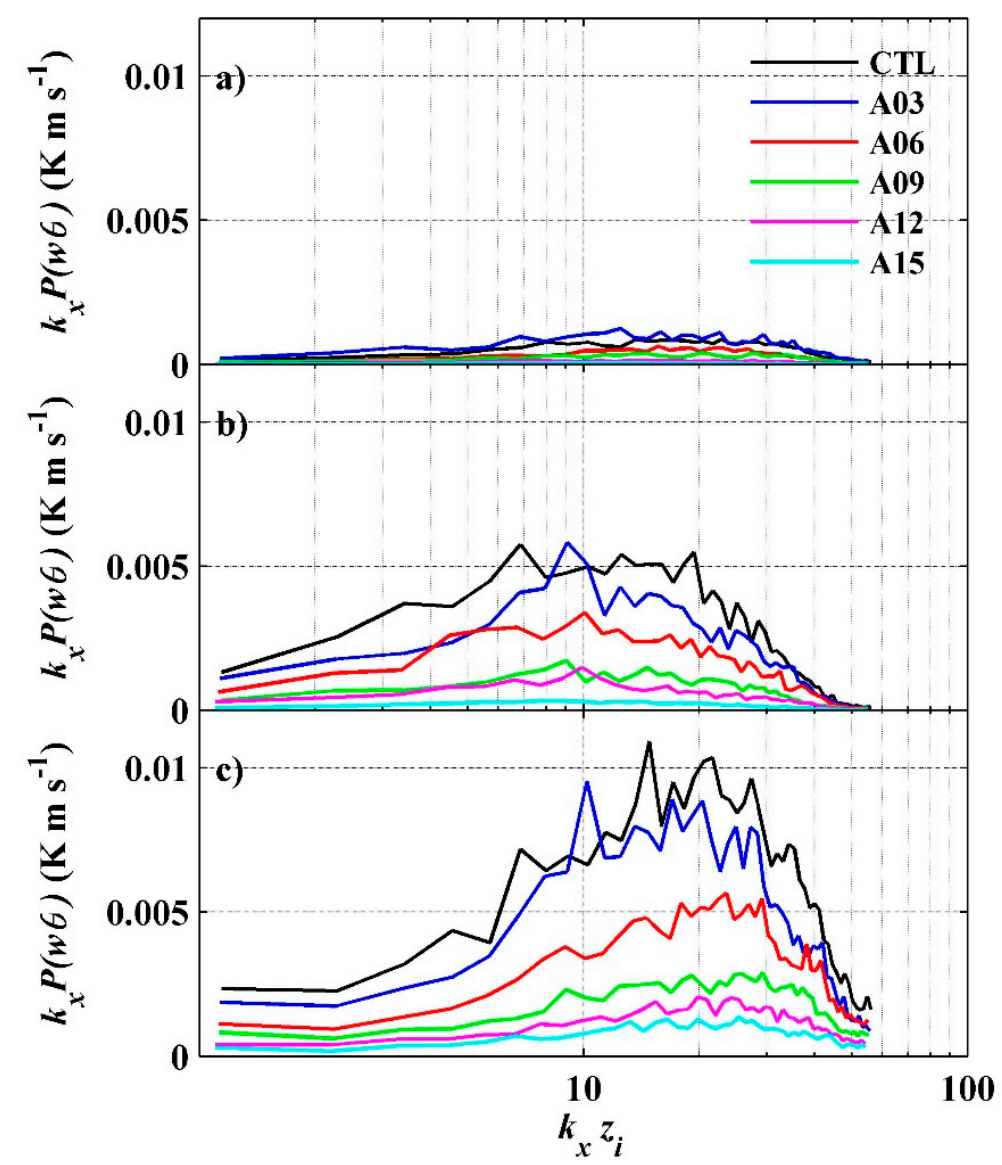

Figure 7. Heat flux $(w-\theta)$ cospectra for the case with different AOD values and the free-atmosphere potential temperature gradient of $6 \mathrm{~K} \mathrm{~km}^{-1}$. The cospectra at the top (a), middle (b), and bottom (c) correspond to the heights $z / z_{i}=0.9,0.5$, and 0.1 , respectively. The color scheme for cases with different AOD is the same as in Figure 6.

\subsection{Profiles of Turbulence Statistics}

Now, we focus on how aerosol radiative heating affects the vertical profiles of meteorological variables. As seen in Figure 8, the profiles of mean potential temperature $\theta$ continue to display a classic three-layered CBL structure consisting of a surface-layer interval with a sharp vertical gradient, a mixed-layer region with nearly constant $\theta$, and an entrainment-zone (capping-inversion) range, which is characterized by a greater temperature gradient than that in the overlying free atmosphere. These basic features are persistent across the entire range of imposed AOD values, and all of the $\theta$ profiles are in general terms similar to that observed in the clear atmosphere $[4,24]$, indicating that the additional heat source associated with the aerosol absorption of shortwave radiation does not essentially affect the shape of $\theta$ profiles in the aerosol-loaded CBL. However, a clear integral warming effect is found throughout the CBL with increased aerosol loading. Due to the stronger capping effect with the thermal stratification of $9 \mathrm{~K} \mathrm{~km}^{-1}$ in the free atmosphere, the CBL tops are reduced from around $1100 \mathrm{~m}$ for the case with the weakest stratification of $3 \mathrm{~K} \mathrm{~km}^{-1}$ (Figure $8 \mathrm{a}$ ) to approximately $820 \mathrm{~m}$ for the case with the strongest stratification of $9 \mathrm{~K} \mathrm{~km}^{-1}$ (Figure $8 \mathrm{~g}$ ). Moreover, the level of the zero potential temperature gradient within the CBL (indicated by horizontal dash line) lowers as the AOD increases. For example, under the stratification of $6 \mathrm{~K} \mathrm{~km}^{-1}$, the height of zero gradient is reduced from about $420 \mathrm{~m}$ in the CTL case to around $240 \mathrm{~m}$ in the A15 case. This suggests that the upper portion of the CBL becomes more stable earlier in cases with stronger aerosol heating as compared to the aerosol-free case (CTL). 

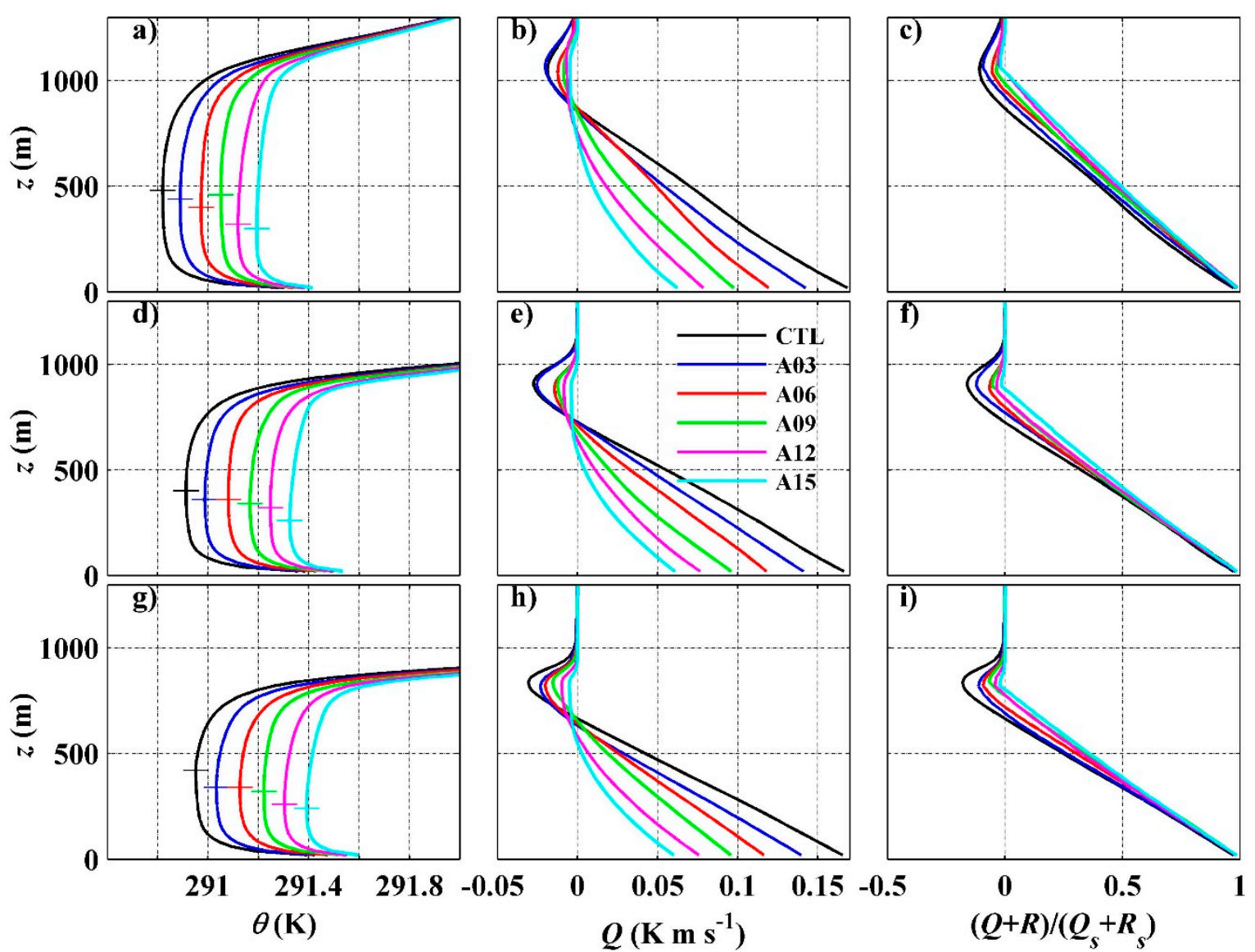

Figure 8. Vertical profiles of potential temperature (left column, a,d,g), vertical kinematic turbulent heat flux (central column, $\mathbf{b}, \mathbf{e}, \mathbf{h}$ ), and total heat flux (right column, $\mathbf{c}, \mathbf{f}, \mathbf{i}$ ) for the cases with three different stratification strengths in the free atmosphere: $3 \mathrm{~K} \mathrm{~km}^{-1}$ (upper row, a,b,c), $6 \mathrm{~K} \mathrm{~km}^{-1}$ (middle row, d,e,f), and $9 \mathrm{~K} \mathrm{~km}^{-1}$ (lower row, g,h,i). Black: $\mathrm{CTL}, \mathrm{AOD}=0$; blue: $\mathrm{A03}, \mathrm{AOD}=0.3$; red: $\mathrm{A} 06, \mathrm{AOD}=0.6$; green: $\mathrm{A} 09, \mathrm{AOD}=0.9$; magenta: $\mathrm{A} 12, \mathrm{AOD}=1.2$; cyan: $\mathrm{A} 15, \mathrm{AOD}=1.5$. The short horizontal dash indicates the position of zero mean $\theta$ gradient. $Q$ : turbulent kinematic heat flux; $R$ : shortwave radiation flux; $Q_{\mathrm{s}}$ : surface heat flux; $R_{\mathrm{s}}$ : surface downward shortwave radiation.

In the aerosol-polluted CBL, potential temperature evolution is determined by the divergence of turbulent kinematic heat flux $(Q)$ and radiation flux $(R)$ [10]. The governing equation for the horizontally averaged potential temperature in a horizontally homogeneous CBL is:

$$
\frac{\partial \theta}{\partial t}=-\frac{\partial Q}{\partial z}-\frac{\partial R}{\partial z}
$$

It is clearly seen in Figure $8 \mathrm{~b}, \mathrm{e}, \mathrm{h}$ that the surface heat flux reduces significantly from $0.17 \mathrm{~K} \mathrm{~m} \mathrm{~s}^{-1}$ (CTL case) to $0.063 \mathrm{~K} \mathrm{~m} \mathrm{~s}^{-1}$ (A15 case) due to the absorption and scattering of aerosols. As expected, the heat flux profiles of aerosol-free CBL (black lines) display a classic linear decrease with height. However, in the CBL with the aerosol shortwave radiation absorption, the heat flux profiles depart from a linear shape, but the total heat (thermal energy) flux (the sum of turbulent heat flux and shortwave radiation flux) remains linear (Figure $8 \mathrm{c}, \mathrm{f}, \mathrm{i}$ ), which is consistent with the approximately well-mixed potential temperature field within the CBL that is shown in Figure 8a,d,g. The retention of height-constant $\theta$ is expected from Equation (2), assuming a linear $Q+R$ profile.

Now, we turn our attention to profiles of variances. Velocity variance is a measure of turbulence intensity that is associated with the fluctuation of a particular velocity component. As demonstrated in Figure 9, the horizontal velocity variance $\left(\overline{u^{\prime 2}}+\overline{v^{\prime 2}}\right)$ displays a three-layer structure similar to 
that of the $\theta$ field, with the strong gradient near the surface, little change in the main portion of the $\mathrm{CBL}$, and an increase within the entrainment layer. All of the demonstrated variance profiles show a similar distribution pattern, but the variance magnitude reduces substantially throughout the CBL with increasing AOD. The peak variance value near the boundary layer top indicates that under the effect of stratification in this region of the flow, the rising motions from updrafts are redirected and transformed into the horizontal turbulent motions. In the presence of aerosol radiative heating, these variance peaks become less protuberant. The aforementioned transformational effect can be quantified by the ratio of vertical velocity variance to horizontal variance $\left(\frac{\overline{w^{\prime 2}}}{\overline{u^{\prime 2}}+\overline{v^{\prime 2}}}\right)$. For the CBL cases with free-atmosphere stratification of $6 \mathrm{~K} \mathrm{~km}^{-1}$, this ratio is reduced from 0.42 in the CTL case to 0.24 in the A15 case, indicating less efficient transfer from vertical to horizontal motions in the CBL with aerosol loading. This effect may be explained by the weakening of capping inversion in the presence of aerosol radiative heating leading to less resistance to rising thermals in comparison with the clean CBL.

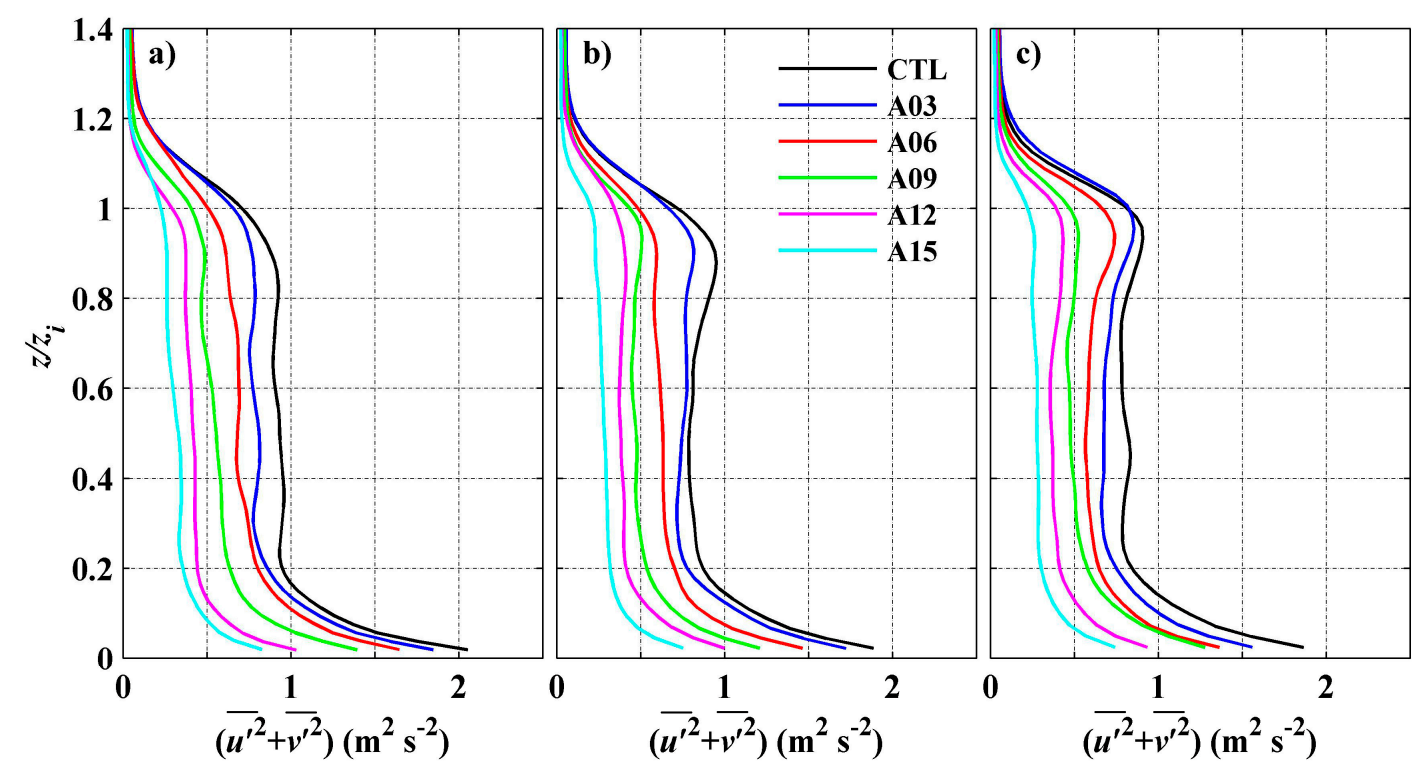

Figure 9. Profiles of total horizontal velocity variance $\left(\overline{u^{\prime 2}}+\overline{v^{\prime 2}}\right)$ for the cases with three different stratification strengths in the free atmosphere: (a) $3 \mathrm{~K} \mathrm{~km}^{-1}$, (b) $6 \mathrm{~K} \mathrm{~km}^{-1}$, and (c) $9 \mathrm{~K} \mathrm{~km}^{-1}$. The color scheme for cases with different AOD is the same as in Figure 8.

The variance of vertical velocity $\overline{\left(w^{\prime 2}\right)}$ that is shown in Figure 10 varies with height rather differently to $\left(\overline{u^{\prime 2}}+\overline{v^{\prime 2}}\right)$. A typical quasi-parabolic shape is found in $\overline{w^{\prime 2}}$ profiles for all of the cases with a maximum value around $z / z_{i}=0.3 \sim 0.35$. Increasing AOD does not modify the $\overline{w^{\prime 2}}$ pattern qualitatively, but it does make the amplitude and curvature of the profiles smaller. For instance, the maximum of $\overline{w^{\prime 2}}$ is reduced by $62 \%$, and the maximum height shifts downward from $z / z_{i}=0.35$ to $z / z_{i}=0.29$ when the $A O D$ increases from 0 to 1.5. The free-atmosphere stratification exerts a pronounced impact on the vertical motion in the CBL. Typically, the magnitude of $\overline{w^{\prime 2}}$ is reduced as the free-atmosphere stratification becomes stronger, indicating that rising motions are inhibited under conditions of stronger stability. 


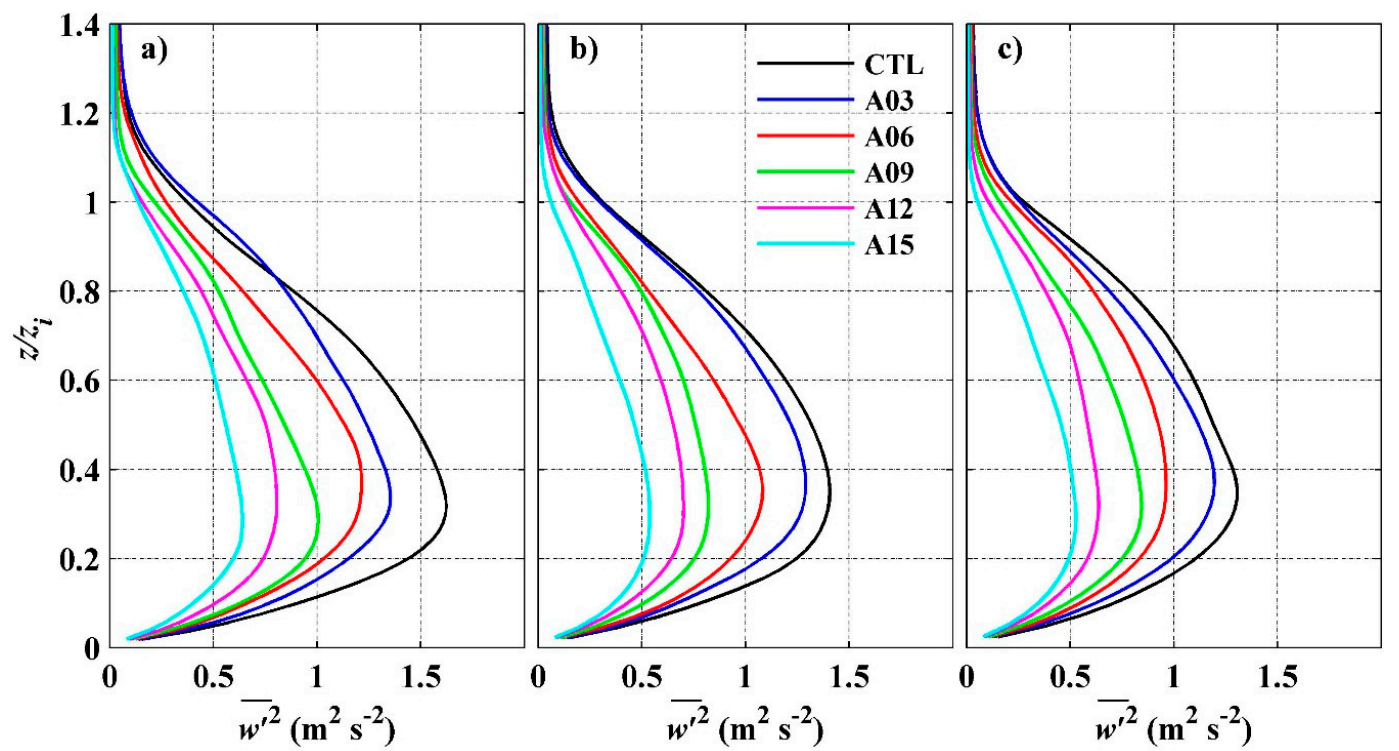

Figure 10. Profiles of vertical velocity variance $\left(\overline{w^{\prime 2}}\right)$ for the cases with three different stratification strengths in the free atmosphere: (a) $3 \mathrm{~K} \mathrm{~km}^{-1}$, (b) $6 \mathrm{~K} \mathrm{~km}^{-1}$, and (c) $9 \mathrm{~K} \mathrm{~km}^{-1}$. The color scheme for cases with different AOD is the same as in Figure 8.

The reduction of both horizontal and vertical velocity variances under conditions of aerosol loading represents the decrease in TKE. This reduction is due to the attenuation of surface heat flux associated with the diminishing of shortwave radiation reaching the surface because of scattering and absorption by aerosols. The absorbed part of solar radiation contributes to heating the CBL air, but it does not enhance TKE [56].

The profiles of potential temperature variance $\left(\overline{\theta^{\prime 2}}\right)$ are very different from the profiles of velocity variances. The variance $\overline{\theta^{\prime 2}}$ is closely associated with the vertical $\theta$ gradient, as has been also found in other LES studies, but for the CBL without the aerosol radiative effect [26,57]. As seen in Figure 11, ${\theta^{\prime 2}}^{2}$ approaches very small values throughout the well-mixed region of CBL where $\theta$ does show a small change, and tends to be much larger in the entrainment zone and near the surface. Consequently, aerosol radiative effect has a strong impact on the profile of $\overline{\theta^{\prime 2}}$. Increasing $A O D$ reduces $\overline{\theta^{\prime 2}}$ substantially both in the entrainment zone and near the surface, while the increased stratification strengthens $\overline{\theta^{\prime 2}}$. Specifically, the peak $\overline{\theta^{\prime 2}}$ at the top of the boundary layer is reduced by $79 \%$, with the $A O D$ increasing from 0 to 1.5 for the free-atmosphere stratification of $6 \mathrm{~K} \mathrm{~km}^{-1}$.

The last statistical parameter to be examined in this study is the skewness of vertical velocity. The vertical velocity skewness $S_{w}$ is defined as $S_{w}=\overline{w^{\prime 3}} /\left(\overline{w^{\prime 2}}\right)^{3 / 2}$. It is known from other studies that in the surface heating-driven CBL, $S_{w}$ is overall positive, and increases with height [28,29]. Figure 12 shows a pattern of $S_{w}$ that is somehow similar to $\overline{w^{\prime 2}}$, but with the maximum value appearing in the upper portion of the $\mathrm{CBL}$, around $z / z_{i}=0.7 \sim 0.8$. The aerosol radiative effect imposes impact on the vertical velocity skewness, $S_{w}$. As revealed by the plot, the increasing AOD reduces the vertical velocity skewness, but it does not change the vertical profile shape in general terms. The strengthening of stratification leads to the drop of the maximum value of $S_{w}$ and reduces the height at which the maximum is achieved. The maximum skewness is reduced by about $32 \%$ as AOD increases from 0 to 1.5 with the stratification of $6 \mathrm{~K} \mathrm{~km}^{-1}$ in the free atmosphere. The reduction suggests that updrafts/thermals become less vigorous as AOD increases. 


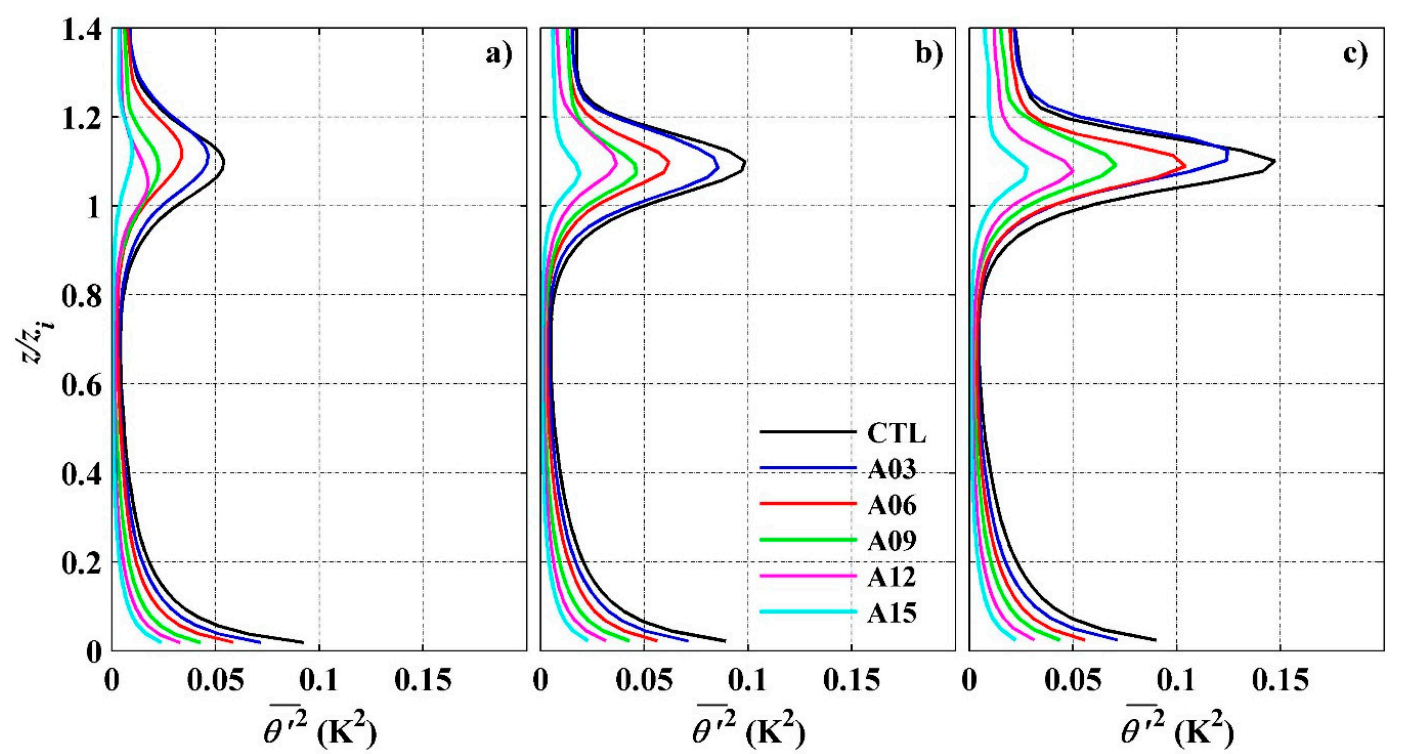

Figure 11. Profiles of potential temperature variance $\left(\overline{\theta^{\prime 2}}\right)$ for the cases with three different stratification strengths in the free atmosphere: (a) $3 \mathrm{~K} \mathrm{~km}^{-1}$, (b) $6 \mathrm{~K} \mathrm{~km}^{-1}$, and (c) $9 \mathrm{~K} \mathrm{~km}^{-1}$. The color scheme for cases with different AOD is the same as in Figure 8.

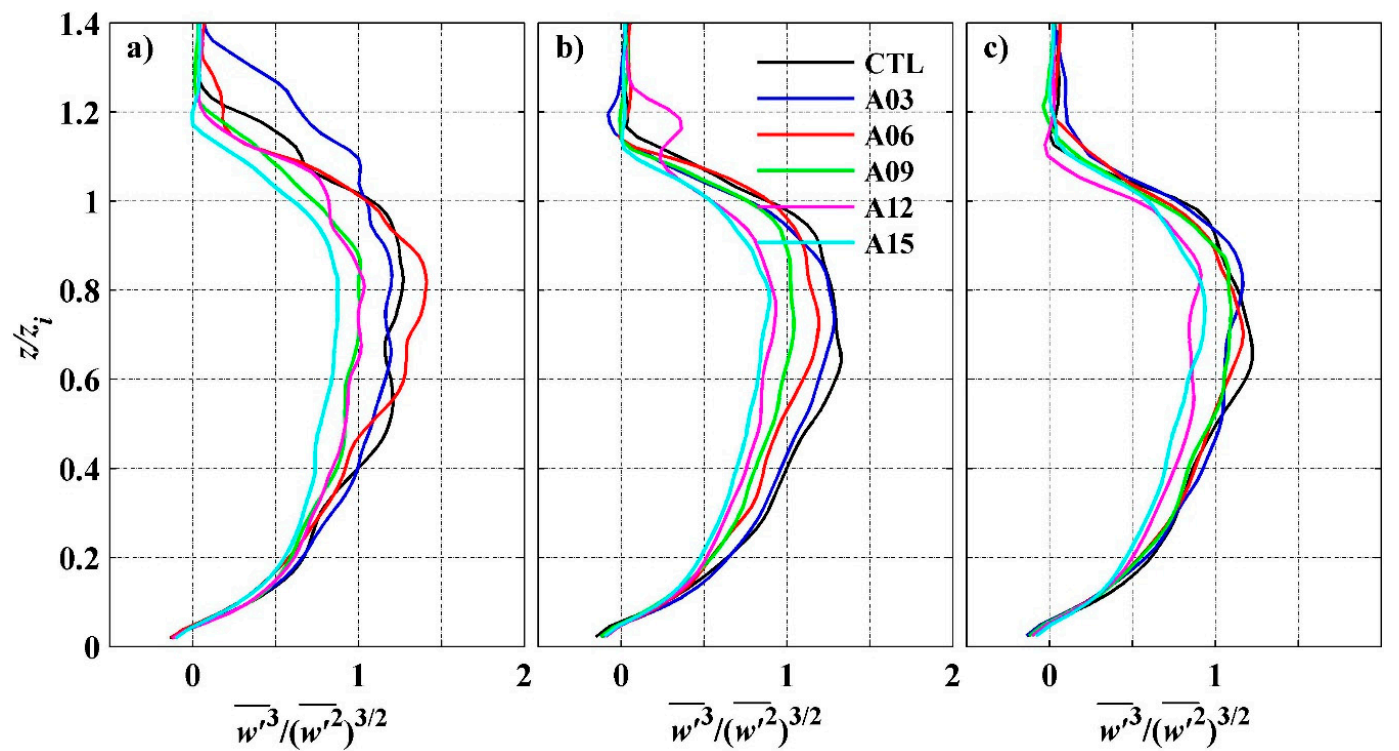

Figure 12. Profiles of vertical velocity skewness $\left(\overline{w^{\prime 3}} /\left(\overline{w^{\prime 2}}\right)^{3 / 2}\right)$ for the cases with three different stratification strengths in the free atmosphere: (a) $3 \mathrm{~K} \mathrm{~km}^{-1}$, (b) $6 \mathrm{~K} \mathrm{~km}^{-1}$, and (c) $9 \mathrm{~K} \mathrm{~km}^{-1}$. The color scheme for cases with different AOD is the same as in Figure 8.

\subsection{Scaling Parameters for Normalization of Statistics}

As discussed above, the radiative effects of both the aerosol and stratification conditions have substantial influences on the turbulence structure in the CBL. However, the profiles of turbulence statistics presented above appear to be rather scattered. Now, we try to identify scaling parameters that would allow to reduce the scatter between profiles corresponding to particular flow realizations, and, in an optimal case, help to collapse the profiles to a universal curve. This is a commonly used approach to analyze flow scenarios with varying initial and forcing conditions $[4,6]$. In the previous study, Liu et al. [39] derived a zero-order model (ZOM) entrainment equation accounting for the aerosol 
radiative heating effect. In op. cit., a modified convective velocity scale $\left(w_{* R}\right)$ is proposed that considers the effect of the aerosol radiative heat flux:

$$
w_{* R} \equiv\left[\frac{g}{\theta_{0}}\left(Q_{s}+R_{s}+R_{i}-\frac{2}{z_{i}} \int_{0}^{z_{i}} R(z) d z\right) z_{i}\right]^{1 / 3}
$$

where $R(z), R_{s}$, and $R_{i}$ are the shortwave radiation flux values at level $z$ within the CBL, at the surface, and at the CBL top, respectively. It is demonstrated in Liu et al. [39] that the modified convective scale is more appropriate for scaling entrainment relationships in the CBL with aerosol radiative heating. Here, in addition to the modified velocity scale, we propose a modified temperature scale $\left(\theta_{* R}\right)$ :

$$
\theta_{* R} \equiv\left(Q_{s}+R_{s}+R_{i}-\frac{2}{z_{i}} \int_{0}^{z_{i}} R(z) d z\right) / w_{* R}
$$

Note that in the absence of aerosol radiative effects, the radiative flux is constant with height, and the modified scales for velocity, as seen in Equation (3), and temperature, as seen in Equation (4), reduce to their traditional forms, which are shown in Equation (1). Both traditional and modified convective velocity and temperature scales are employed below to normalize the profiles of vertical velocity variances and potential temperature variances in order to evaluate the robustness of the proposed scaling parameters.

The dimensionless profiles of vertical velocity variances normalized with two different sets of scaling parameters are illustrated in Figure 13. It is seen that the vertical velocity variances for different AOD normalized by traditional $w_{*}^{2}$ are close to each other up to $z / z_{i}=0.2$, but fail to converge above this level, especially within the entrainment zone (see upper panels in Figure 13). A possible reason for such divergence is that the impact of aerosol heating is more pronounced in the upper portion of the boundary layer, where radiative heating significantly affects the parameters of turbulence. This effect is not represented in the traditional convective velocity scale. With the modified convective velocity scale $w_{* R}$ employed, all of the lines in the lower panels follow each other more closely throughout the entire $\mathrm{CBL}$, clearly demonstrating the relevance of the modified convective velocity scale for characterizing the turbulence structure in the aerosol-loaded CBL.

The dimensionless potential temperature variances normalized with two different temperature scales are presented in Figure 14. In the upper panels showing results with the traditional scaling, all of the lines overlap from the ground to the middle portion of the CBL, but diverge noticeably within the entrainment zone as AOD varies. This is apparently a result of leaving out the aerosol heating effect. With the modified temperature scale used, the lines in the lower panels show a more universal pattern throughout the entire CBL, further suggesting that the modified temperature scale is appropriate for the CBL with aerosol heating conditions. 

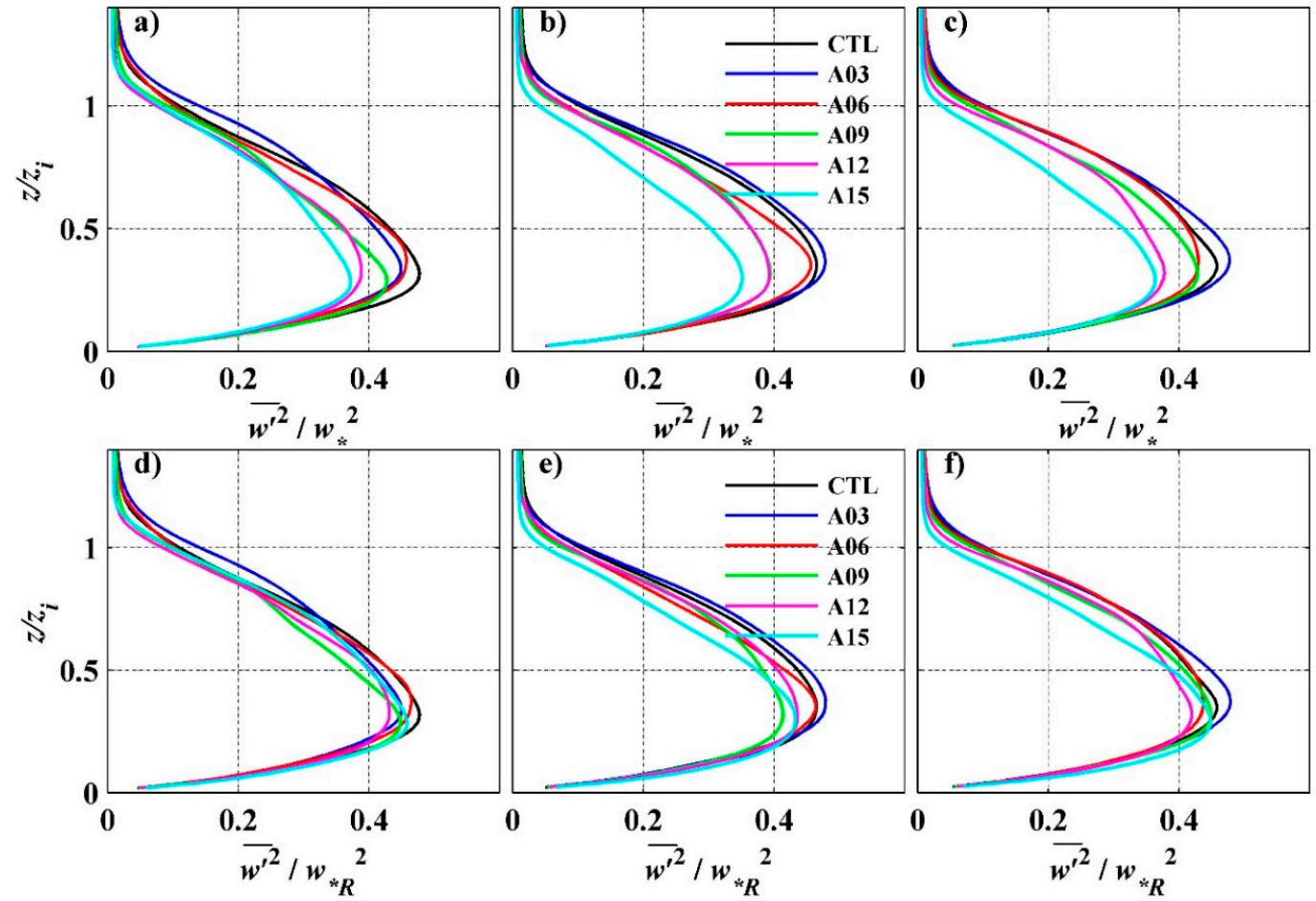

Figure 13. A comparison of profiles of the vertical velocity variance $\left(\overline{w^{\prime 2}}\right)$ normalized with traditional convective velocity scale $w_{*}:(\mathbf{a}-\mathbf{c})$ and modified convective velocity scale $w_{* R}:(\mathbf{d}-\mathbf{f})$ for three different stratification strengths in the free atmosphere. For notation, see Figure 10.
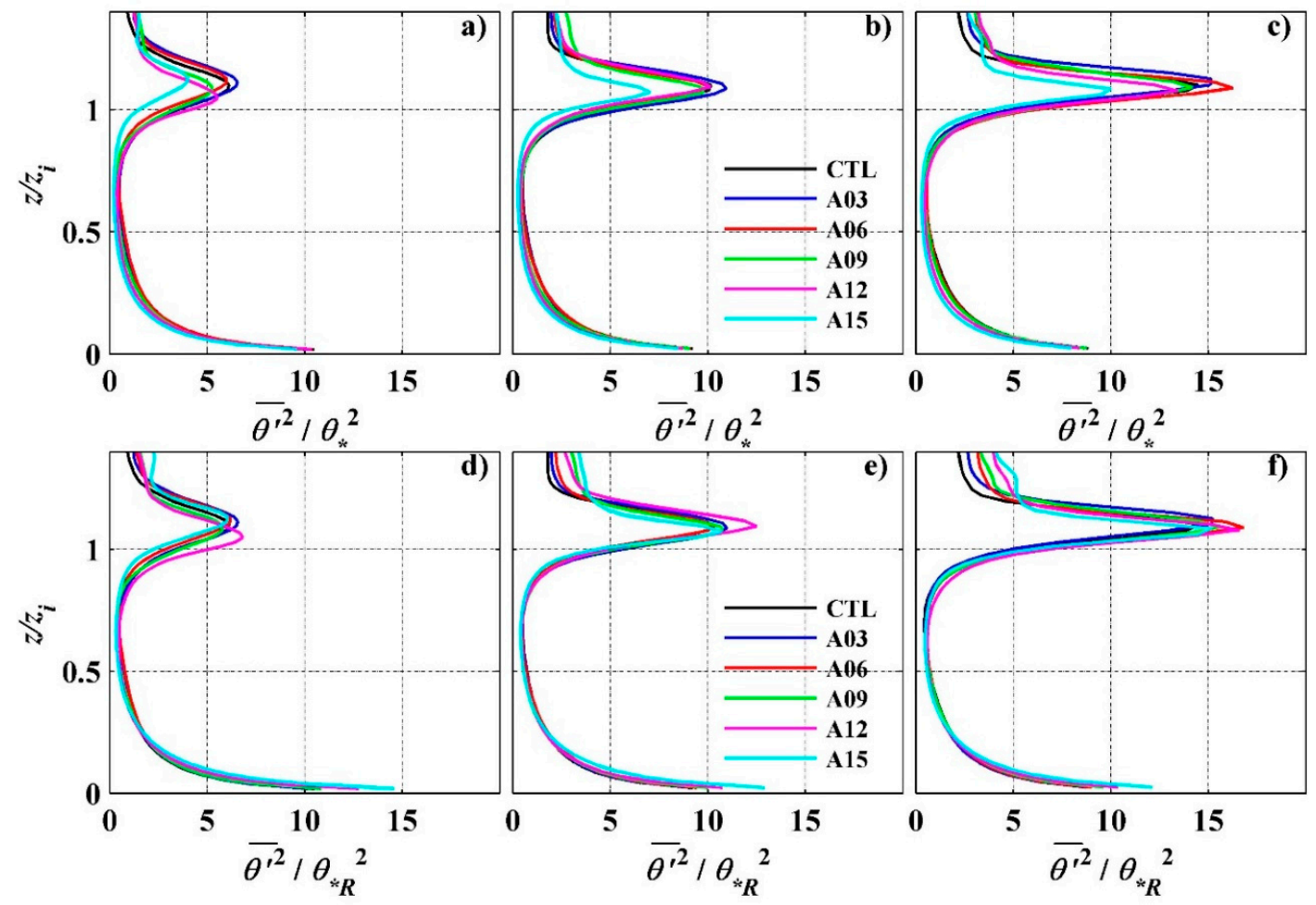

Figure 14. A comparison of profiles of the potential temperature variance $\left(\overline{\theta^{\prime 2}}\right)$ normalized traditional temperature scale $\theta_{*}:(\mathbf{a}-\mathbf{c})$ and modified temperature scale $\theta_{* R}:(\mathbf{d}-\mathbf{f})$ for three different stratification strengths in the free atmosphere. For notation, see Figure 11. 


\section{Summary and Conclusions}

In this study, the turbulence statistics and spectra in the CBL with aerosol radiative heating have been investigated by using a series of numerical experiment results conducted with a LES code coupled with a radiative transfer model. The results show that the aerosol radiative effect exerts a significant impact on the turbulence structure in the CBL with varying aerosol conditions. The potential temperature continues to show three-layered structures, even when the aerosol radiative effect is included. However, in the presence of aerosols, the turbulent heat flux does not follow a linear relationship with the height characteristics of a clean CBL. Increasing the AOD reduces the variances of horizontal and vertical velocity as well as potential temperature, but does not generally modify the profile patterns.

The spectral densities of both the horizontal and vertical velocity components in the CBL with an aerosol radiative effect continue to follow the Kolmogorov's $-5 / 3$ law in the inertial subrange. As AOD increases, the shapes of the horizontal and vertical component spectra remain practically unchanged, but the spectral densities become smaller overall, and the peaks of the velocity spectra are shifted toward larger wavenumbers. This indicates that the energy-containing turbulent eddies become smaller with an increase of the aerosol loading, which is supported by the visualized distributions of vertical velocity over the $x-y$ planes.

By employing the modified velocity and temperature scales that have an included aerosol radiative effect, the profiles of normalized vertical velocity variances and potential temperature variances for different aerosol pollution cases converge throughout the entire CBL. This emphasizes the importance of using modified scaling parameters for analyses of the turbulence structure of the aerosol-loaded CBL.

In the future, more aerosol parameter settings such as the vertical distribution of aerosol and other aerosol properties (e.g., single scattering albedo) need to be considered in order to further evaluate the impact of aerosol radiative effect on the turbulence structure of the aerosol-loaded CBL.

Author Contributions: J.H. and E.F. proposed the idea and supervised the work. C.L. and X.-M.H. coupled the code and performed the experiments. C.L. drew all of the figures and wrote the original draft. J.H., E.F., X.L., Y.W., X.-M.H. reviewed and revised the manuscript.

Funding: The research was supported jointly by the National Key Research and Development Program of China (Grant 2017YFC0210102), the National Natural Science Foundation of China (Grant 41575009), Postgraduate Research and Practice Innovation Program of Jiangsu Province (Grant KYLX16_0945), and the Priority Academic Program Development of Jiangsu Higher Education Institutions (PAPD).

Acknowledgments: The computing for this project was performed at the OU Supercomputing Center for Education and Research (OSCER) at the University of Oklahoma (OU).

Conflicts of Interest: The authors declare no conflicts of interest.

\section{References}

1. Smith, F.B. Turbulence in the atmospheric boundary layer. Sci. Prog. 1975, 62, 127-151.

2. Fedorovich, E.; Conzemius, R.; Mironov, D. Convective entrainment into a shear-free, linearly stratified atmosphere: Bulk models reevaluated through large eddy simulations. J. Atmos. Sci. 2004, 61, $281-295$. [CrossRef]

3. Liu, C.; Feorovich, E.; Huang, J. Revisiting entrainment relationships for shear-free and sheared convective boundary layers through large-eddy simulations. Q. J. R. Meteorol. Soc. 2018. [CrossRef]

4. Stull, R.B. An Introduction to Boundary Layer Meteorology; Kluwer Academic Publishers: Alphen aan den Rijn, The Netherlands, 1988.

5. Oboukhov, A.M. Some specific features of atmospheric tubulence. J. Fluid Mech. 1962, 13, 77-81. [CrossRef]

6. Nieuwstadt, F.T.M.; Duynkerke, P.G. Turbulence in the atmospheric boundary layer. Atmos. Res. 1996, 40, 111-142. [CrossRef]

7. Lee, X.; Gao, Z.; Zhang, C.; Chen, F.; Hu, Y.; Jiang, W.; Liu, S.; Lu, L.; Sun, J.; Wang, J.; et al. Priorities for boundary layer meteorology research in China. Bull. Am. Meteorol. Soc. 2015, 96, ES149-ES151. [CrossRef] 
8. Yu, H.; Liu, S.C.; Dickinson, R.E. Radiative effects of aerosols on the evolution of the atmospheric boundary layer. J. Geophys. Res. Atmos. 2002, 107, 4142. [CrossRef]

9. Kedia, S.; Ramachandran, S.; Kumar, A.; Sarin, M.M. Spatiotemporal gradients in aerosol radiative forcing and heating rate over Bay of Bengal and Arabian Sea derived on the basis of optical, physical, and chemical properties. J. Geophys. Res. Atmos. 2010, 115, D07205. [CrossRef]

10. Barbaro, E.; Vilà-Guerau de Arellano, J.; Krol, M.C.; Holtslag, A.A. Impacts of aerosol shortwave radiation absorption on the dynamics of an idealized convective atmospheric boundary layer. Bound.-Layer Meteorol. 2013, 148, 31-49. [CrossRef]

11. Ding, A.J.; Huang, X.; Nie, W.; Sun, J.N.; Kerminen, V.M.; Petäjä, T.; Su, H.; Cheng, Y.F.; Wang, X.Q.; Wang, M.H.; et al. Enhanced haze pollution by black carbon in megacities in China. Geophys. Res. Lett. 2016, 43, 2873-2879. [CrossRef]

12. Li, Z.; Guo, J.; Ding, A.; Liao, H.; Liu, J.; Sun, Y.; Wang, T.; Xue, H.; Zhang, H.; Zhu, B. Aerosol and boundary-layer interactions and impact on air quality. Natl. Sci. Rev. 2017, 4, 810-833. [CrossRef]

13. Angevine, W.M.; Grimsdell, A.W.; McKeen, S.A.; Warnock, J.M. Entrainment results from the Flatland boundary layer experiments. J. Geophys. Res. Atmos. 1998, 103, 13689-13701. [CrossRef]

14. Raga, G.B.; Castro, T.; Baumgardner, D. The impact of megacity pollution on local climate and implications for the regional environment: Mexico City. Atmos. Environ. 2001, 35, 1805-1811. [CrossRef]

15. Gao, Y.; Zhang, M.; Liu, Z.; Wang, L.; Wang, P.; Xia, X.; Tao, M.; Zhu, L. Modeling the feedback between aerosol and meteorological variables in the atmospheric boundary layer during a severe fog-haze event over the North China Plain. Atmos. Chem. Phys. 2015, 15, 4279-4295. [CrossRef]

16. Qiu, Y.; Liao, H.; Zhang, R.; Hu, J. Simulated impacts of direct radiative effects of scattering and absorbing aerosols on surface-layer aerosol concentrations in China during a heavily polluted event in February 2014. J. Geophys. Res. Atmos. 2017, 122, 5955-5975. [CrossRef]

17. Ackerman, T.P. A model of the effect of aerosols on urban climates with particular applications to the Los Angeles basin. J. Atmos. Sci. 1977, 34, 531-547. [CrossRef]

18. Deardorff, J.W. 1972: Numerical investigation of neutral and unstable planetary boundary layers. J. Atmos. Sci. 1972, 29, 91-115. [CrossRef]

19. Moeng, C.H. A large-eddy-simulation model for the study of planetary boundary-layer turbulence. J. Atmos. Sci. 1984, 41, 2052-2062. [CrossRef]

20. Sullivan, P.P.; McWilliams, J.C.; Moeng, C.H. A grid nesting method for large-eddy simulation of planetary boundary-layer flows. Bound.-Layer Meteorol. 1996, 80, 167-202. [CrossRef]

21. Huang, J.; Lee, X.; Patton, E.G. Dissimilarity of scalar transport in the convective boundary layer in inhomogeneous landscapes. Bound.-Layer Meteorol. 2009, 130, 327-345. [CrossRef]

22. Huang, J.; Lee, X.; Patton, E.G. Entrainment and budgets of heat, water vapor, and carbon dioxide in a convective boundary layer driven by time-varying forcing. J. Geophys. Res. Atmos. 2011, 116, D06308. [CrossRef]

23. Archer-Nicholls, S.; Lowe, D.; Schultz, D.M.; McFiggans, G. Aerosol-radiation-cloud interactions in a regional coupled model: The effects of convective parameterization and resolution. Atmos. Chem. Phys. 2016, 16, 5573-5594. [CrossRef]

24. Kaimal, J.C.; Wyngaard, J.C.; Haugen, D.A.; Coté, O.R.; Izumi, Y.; Caughey, S.J.; Readings, C.J. Turbulence structure in the convective boundary layer. J. Atmos. Sci. 1976, 33, 2152-2169. [CrossRef]

25. Huang, J.; Lee, X.; Patton, E.G. A modelling study of flux imbalance and the influence of entrainment in the convective boundary layer. Bound.-Layer Meteorol. 2008, 127, 273-292. [CrossRef]

26. Sullivan, P.P.; Moeng, C.H.; Stevens, B.; Lenschow, D.H.; Mayor, S.D. Structure of the entrainment zone capping the convective atmospheric boundary layer. J. Atmos. Sci. 1998, 55, 3042-3064. [CrossRef]

27. Moeng, C.H.; Sullivan, P.P.; Stevens, B. Including radiative effects in an entrainment rate formula for buoyancy-driven PBLs. J. Atmos. Sci. 1999, 56, 1031-1049. [CrossRef]

28. Moeng, C.H.; Rotunno, R. Vertical-velocity skewness in the buoyancy-driven boundary layer. J. Atmos. Sci. 1990, 47, 1149-1162. [CrossRef]

29. Hogan, R.J.; Grant, A.L.; Illingworth, A.J.; Pearson, G.N.; O'Connor, E.J. Vertical velocity variance and skewness in clear and cloud-topped boundary layers as revealed by Doppler lidar. Q. J. R. Meteorol. Soc. 2009, 135, 635-643. [CrossRef] 
30. Deardorff, J.W. Convective velocity and temperature scales for the unstable planetary boundary layer and for Rayleigh convection. J. Atmos. Sci. 1970, 27, 1211-1213. [CrossRef]

31. Lee, X. Turbulence spectra and eddy diffusivity over forests. J. Appl. Meteo. 1996, 35, 1307-1318. [CrossRef]

32. Kaimal, J.C.; Wyngaard, J.C.; Izumi, Y.; Coté, O.R. Spectral characteristics of surface-layer turbulence. Q. J. R. Meteorol. Soc. 1972, 98, 563-589. [CrossRef]

33. Moraes, O.L.; Fitzjarrald, D.R.; Acevedo, O.C.; Sakai, R.K.; Czikowsky, M.J.; Degrazia, G.A. Comparing spectra and cospectra of turbulence over different surface boundary conditions. Phys. A Stat. Mech. Appl. 2008, 387, 4927-4939. [CrossRef]

34. Moeng, C.H.; Wyngaard, J.C. Spectral analysis of large-eddy simulations of the convective boundary layer. J. Atmos. Sci. 1988, 45, 3573-3587. [CrossRef]

35. Schmidt, H.; Schumann, U. Coherent structure of the convective boundary layer derived from large-eddy simulations. J. Fluid Mech. 1989, 200, 511-562. [CrossRef]

36. Sullivan, P.P.; Patton, E.G. The effect of mesh resolution on convective boundary layer statistics and structures generated by large-eddy simulation. J. Atmos. Sci. 2011, 68, 2395-2415. [CrossRef]

37. Gibbs, J.A.; Fedorovich, E. Effects of temporal discretization on turbulence statistics and spectra in numerically simulated convective boundary layers. Bound.-Layer Meteorol. 2014, 153, 19-41. [CrossRef]

38. Gibbs, J.A.; Fedorovich, E. Comparison of convective boundary layer velocity spectra retrieved from large-eddy-simulation and weather research and forecasting model data. J. Appl. Meteorol. Climatol. 2014, 53, 377-394. [CrossRef]

39. Liu, C.; Fedorovich, E.; Huang, J.; Hu, X.M.; Wang, Y.; Lee, X. Impact of aerosol shortwave radiative heating on the entrainment in atmospheric convective boundary layer: A large-eddy simulation study. J. Atmos. Sci. 2018. in revision.

40. Patton, E.G.; Sullivan, P.P.; Moeng, C.H. The influence of idealized heterogeneity on wet and dry planetary boundary layers coupled to the land surface. J. Atmos. Sci. 2005, 62, 2078-2097. [CrossRef]

41. Ricchiazzi, P.; Yang, S.; Gautier, C.; Sowle, D. SBDART: A research and teaching software tool for plane-parallel radiative transfer in the Earth's atmosphere. Bull. Amer. Meteor. Soc. 1998, 79, 2101-2114. [CrossRef]

42. Steyn, D.G.; Baldi, M.; Hoff, R.M. The detection of mixed layer depth and entrainment zone thickness from lidar backscatter profiles. J. Atmos. Ocean Technol. 1999, 16, 953-959. [CrossRef]

43. Ferrero, L.; Riccio, A.; Perrone, M.G.; Sangiorgi, G.; Ferrini, B.S.; Bolzacchini, E. Mixing height determination by tethered balloon-based particle soundings and modeling simulations. Atmos. Res. 2011, 102, 145-156. [CrossRef]

44. Ware, J.; Kort, E.A.; DeCola, P.; Duren, R. Aerosol lidar observations of atmospheric mixing in Los Angeles: Climatology and implications for greenhouse gas observations. J. Geophys. Res. Atmos. 2016, 121, 9862-9878. [CrossRef] [PubMed]

45. Liou, K.N. An Introduction to Atmospheric Radiation; Academic Press: New York, NY, USA, 2002.

46. Kleeman, M.J.; Cass, G.R.; Eldering, A. Modeling the airborne particle complex as a source- oriented external mixture. J. Geophys. Res. Atmos. 1997, 102, 21355-21372. [CrossRef]

47. Riemer, N.; Vogel, H.; Vogel, B.; Fiedler, F. Modeling aerosols on the mesoscale- $\gamma$ : Treatment of soot aerosol and its radiative effects. J. Geophys. Res. Atmos. 2003, 108. [CrossRef]

48. Pino, D.; Vilà-Guerau De Arellano, J. Effects of shear in the convective boundary layer: Analysis of the turbulent kinetic energy budget. Acta Geophys. 2008, 56, 167-193. [CrossRef]

49. Kaufman, Y.J. Aerosol optical thickness and atmospheric path radiance. J. Geophys. Res. Atmos. 1993, 98, 2677-2692. [CrossRef]

50. Tao, M.; Chen, L.; Xiong, X.; Zhang, M.; Ma, P.; Tao, J.; Wang, Z. Formation process of the widespread extreme haze pollution over northern China in January 2013: Implications for regional air quality and climate. Atmos. Environ. 2014, 98, 417-425. [CrossRef]

51. Liu, J.; Zheng, Y.; Li, Z.; Flynn, C.; Cribb, M. Seasonal variations of aerosol optical properties, vertical distribution and associated radiative effects in the Yangtze Delta region of China. J. Geophys. Res. Atmos. 2012, 117. [CrossRef]

52. Klemp, J.B.; Durran, D.R. An upper boundary condition permitting internal gravity wave radiation in numerical mesoscale models. Mon. Weather Rev. 1983, 111, 430-444. [CrossRef] 
53. Kanda, M.; Inagaki, A.; Letzel, M.O.; Raasch, S.; Watanabe, T. LES study of the energy imbalance problem with eddy covariance fluxes. Bound.-Layer Meteorol. 2004, 110, 381-404. [CrossRef]

54. Su, H.B.; Paw U, K.T.; Shaw, R.H. Development of a coupled leaf and canopy model for the simulation of plant-atmosphere interaction. J. Appl. Meteorol. 1996, 35, 733-748. [CrossRef]

55. Kaiser, R.; Fedorovich, E. Turbulence spectra and dissipation rates in a wind tunnel model of the atmospheric convective boundary layer. J. Atmos. Sci. 1998, 55, 580-594. [CrossRef]

56. Barbaro, E.W. Interactions between Aerosal and Convective Boundary-Layer Dynamics over Land; Wageningen University: Wageningen, The Netherlands, 2015.

57. Sorbjan, Z. Effects caused by varying the strength of the capping inversion based on a large eddy simulation model of the shear-free convective boundary layer. J. Atmos. Sci. 1996, 53, 2015-2024. [CrossRef]

(c) 2018 by the authors. Licensee MDPI, Basel, Switzerland. This article is an open access article distributed under the terms and conditions of the Creative Commons Attribution (CC BY) license (http:// creativecommons.org/licenses/by/4.0/). 